\title{
La Révolution algérienne dans Paris Match : construction d'une mémoire photographique (1954-1962)
}

Fadila Yahou

\section{CpenEdition}

Journals

Édition électronique

URL : https://journals.openedition.org/coma/5291

DOI : $10.4000 /$ coma.5291

ISSN : 2275-1742

Éditeur

Institut des textes \& manuscrits modernes (ITEM)

Référence électronique

Fadila Yahou, «La Révolution algérienne dans Paris Match : construction d'une mémoire photographique (1954-1962) », Continents manuscrits [En ligne], 14 | 2020, mis en ligne le 01 avril 2020, consulté le 12 janvier 2023. URL : http://journals.openedition.org/coma/5291 ; DOI : https://doi.org/ 10.4000/coma.5291

Ce document a été généré automatiquement le 12 janvier 2023.

\section{(i) 89

Creative Commons - Attribution - Pas d'Utilisation Commerciale - Pas de Modification 4.0 International - CC BY-NC-ND 4.0

https://creativecommons.org/licenses/by-nc-nd/4.0/ 


\title{
La Révolution algérienne dans Paris Match : construction d'une mémoire photographique (1954-1962)
}

\author{
Fadila Yahou
}

Lors du déclenchement de la Révolution algérienne, Paris Match en fait l'annonce en Une du numéro 293, du 6 au 13 novembre 1954, par l'encart suivant: "LA VAGUE TERRORISTE A FRANCHI LA FRONTIÈRE DE L'ALGÉRIE ». Cette proclamation détonante ne surprendrait pas si elle ne côtoyait une photographie affriolante de l'actrice Gina Lollobrigida. 
Fig. 1.

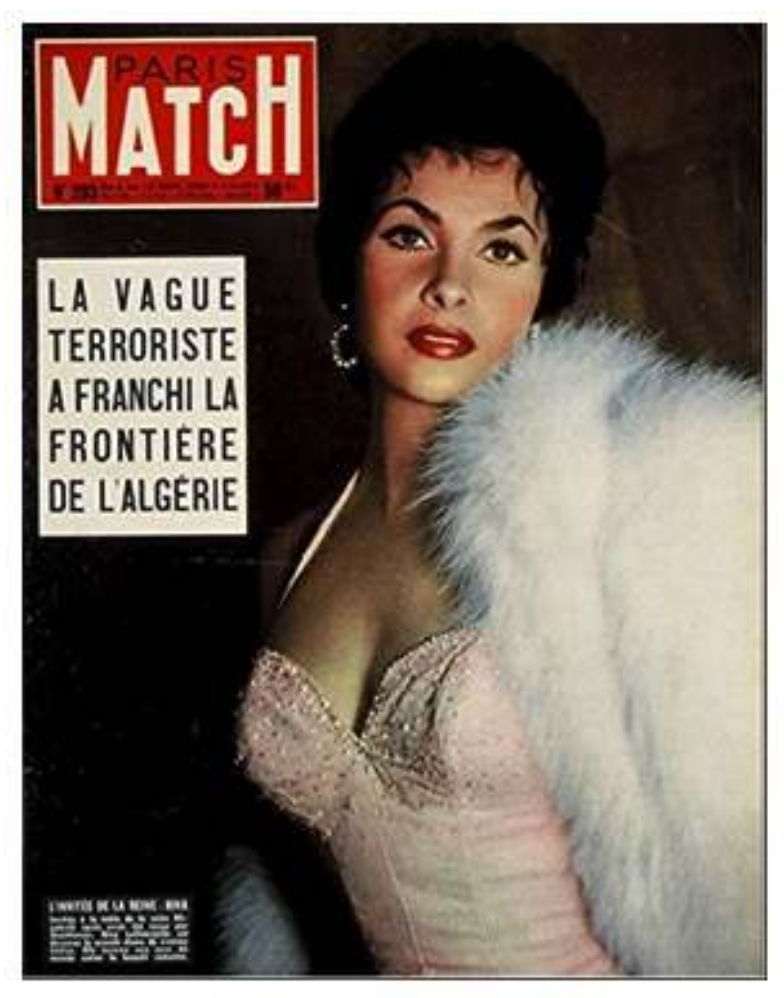

Paris Match, n² 293, du 6 au 13 novembre 1954.

(C) D.R.

Cette combinaison abrupte est symptomatique du traitement de l'information par Paris Match, lui-même emblématique de son époque. De novembre 1954 à septembre 1962, les numéros successifs de Paris Match nous renseignent sur la France des Trente Glorieuses. Elle est insouciante. Elle découvre les joies du confort, de la société de consommation, le twist, le jazz et la vitesse en voiture. La France ne paraît presque pas en guerre. Le magazine se veut le symbole d'un pays en pleine reconstruction après la Seconde Guerre mondiale et heureux d'avoir regagné sa liberté. En effet, l'American way of life fascine et se diffuse après la Seconde Guerre mondiale. De 1954 à 1962, vendu à plus d'un million et demi d'exemplaires, le magazine d'actualité hebdomadaire, touche un large public ${ }^{1}$. Et à la manière de Life, sa formule consiste à couvrir les bouleversements du monde, l'actualité internationale et nationale tout en documentant l'évolution du monde, les premières DS, les avancées technologiques et médicales et les exploits sportifs. Il y étale surtout les réussites et les déboires des rois et des reines, des princes et des princesses, des vedettes et des stars.

2 L'actualité algérienne, mise en spectacle, dramatisée ou minimisée selon l'évolution du conflit, se dilue dans l'actualité économique, politique, sociale, " people ", du pays et du monde. L'intensification de la société du loisir contribue à masquer le conflit, du moins, à le distancer de manière significative. La guerre ne se déroule pas - encore - sur le territoire métropolitain et apparaît ainsi bien lointaine.

3 En outre, bien que l'Occupation soit terminée, la propagande et la censure sévissent toujours; le gouvernement parle de "pacification ", d' « opérations de police » et la censure s'abat sur de nombreux journaux de gauche et/ou militant ${ }^{2}$. Plus réfractaires à la politique coloniale, selon Christophe Barthélémy, « les saisies en métropole touchent 
entre 1955 et 1957, à quelques rares exceptions près, uniquement des journaux de gauche et d'extrême gauche. À partir de 1958 des journaux de droite sont saisis (deux en 1958, 1960 et 1961) plus fréquemment en 1962 (onze journaux soit près d'un tiers des saisies), les journaux d'extrême droite sont saisis à partir de 1959 et ils représentent de 1959 à 1962 entre un sixième et un tiers des saisies ${ }^{3}$."

Paris Match documente ainsi les grandes étapes de la guerre et accorde une place de choix à la photographie. En cela, il constitue un cas d'étude exceptionnel. Aux Unes encore aujourd'hui légendaires, les nombreuses images publiées durant la guerre d'indépendance algérienne sont des témoignages historiques uniques. D'autant que, proche du pouvoir, il échappe à la censure. Cet atout, non négligeable, lui autorise une liberté de ton et de traitement sans égal. Son alignement sur la ligne gouvernementale fait aussi sa faiblesse et son équivoque. Appartient-il alors à une presse d'opinion ou de propagande? Quelle vision de la guerre véhicule-t-il ? Et surtout, dans quelle mesure les images diffusées ont-elles contribué à construire la mémoire que nous avons aujourd'hui du conflit?

5 Pour donner quelques éléments de réponse, il nous a semblé nécessaire de privilégier, en source principale, les archives de la revue. Hebdomadaire, Paris Match publie quatre numéros par mois. Disponibles à la Bibliothèque nationale de France, en microfilms de 1954 à 1959 et en ouvrages reliés à partir de 1960, plus de 330 numéros ont ainsi fait l'objet d'un dépouillement minutieux, de novembre 1954 à septembre 1962. Dans la perspective d'une Histoire visuelle, il est question d'étudier les photographies publiées par la revue. Les gros titres et les légendes, quand ils orientent considérablement le propos, nous ont semblé tout aussi essentiels.

6 Il s'agit ainsi de préciser la démarche journalistique de la revue en proposant une analyse des représentations qu'elle a choisi de diffuser sur la guerre. Nous allons voir, tout au long de cet article et à travers différents exemples, que le traitement du conflit évolue au gré des évènements politiques et militaires tandis que la veine partisane et le positionnement idéologique du magazine demeurent inchangés.

7 Contrairement aux terminologies employées par le pouvoir, le magazine nomme la guerre dès 1955. Il emploie toutefois une dramatisation constante du discours - à travers les titres et légendes - qui contraste avec le choix d'images anecdotiques, niant ou édulcorant le contexte de guerre. Son point de vue se centre sur les militaires et la perspective métropolitaine et française ${ }^{4}$. Lors du déclenchement de la guerre, il rapporte par exemple la série d'attentats déclarant le début de la Révolution algérienne mais surtout l'arrivée de la nouvelle à Paris ainsi que la réaction de l'exécutif5.

Deux périodes se distinguent nettement. Durant la première, jusqu'en 1959, qui correspond à la déclaration du général de Gaulle sur l'autodétermination, la France apparaît à travers ses représentants politiques, ses militaires ou la population française d'Algérie. L'arrivée du général de Gaulle ravit les éditeurs de la revue et il est constamment encensé. Lorsqu'il déclare le "droit à l'autodétermination », Paris Match s'aligne sans difficulté. Quant aux Algériens, lorsqu'ils sont montrés, ils sont diabolisés. Durant la seconde période, à partir de 1960, alors que la guerre arrive en métropole et que des négociations s'organisent, le langage change ; le magazine insiste dès lors sur les notions de «fraternisation », de " paix » et sur la mort des civils. La monstration de la guerre se fait à travers des images tantôt anecdotiques tantôt spectaculaires mais toujours orientées par des légendes ou des mises en scènes. À tel point que nous pourrions nous demander dans quelle mesure cette démarche ne s'apparente pas plus à 
une volonté de choquer ou de provoquer l'intérêt du lecteur que d'informer véritablement. Le ton général de la revue se fait racoleur, presque systématiquement sensationnel, les nombreuses Unes, alliant annonces détonantes sur la guerre et photographies d'actrices affriolantes sont à cet égard édifiantes ${ }^{6}$.

Fig. 2.

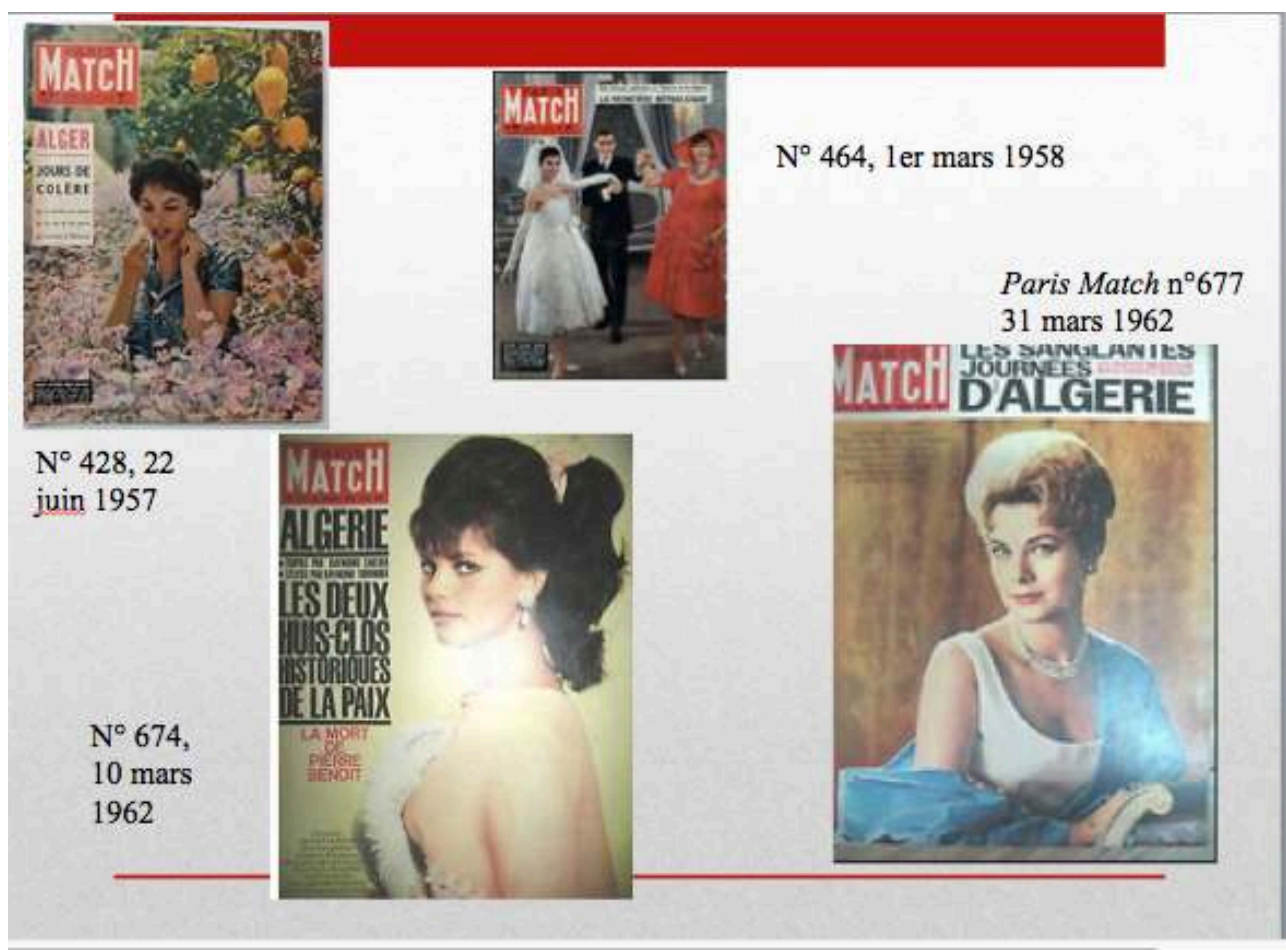

Florilège de couvertures.

(c) D.R.

La rédaction orchestre, en effet, par des mises en page et des légendes, des mises en scènes marquées idéologiquement, en particulier pour les reportages photographiques ${ }^{7}$.

9 Si bien que, dans les formats adoptés, les exemples que nous verrons se rapprochent quelquefois du roman-photo, d'autres fois du roman noir ou encore du fait divers ${ }^{8}$. Ces formes contribuent à faire apparaître la guerre comme anecdotique, voire même fictionnelle. Du moins, à montrer la supériorité de la France et sa maitrise de la situation. La présence d'articles de fond, avec des analyses quelquefois plutôt pertinentes, compensent néanmoins une distorsion fréquente entre l'image et les légendes ou le texte. Il est toutefois incertain que les lecteurs lisaient les articles dans leur intégralité surtout lorsque leurs longueurs s'avéraient importantes. Il apparaît en revanche plus probable qu'en feuilletant le magazine, les images n'ont pu leurs échapper.

\section{Une équipe remarquable de photoreporters}

Conscient de l'influence de la photographie sur les consciences et pour intéresser ses lecteurs, Paris Match s'entoure de rédacteurs de talent, plutôt marqués à droite - Jean Farran, Raymond Cartier, Pierre Joffroy, Jean-Raymond Tournoux ${ }^{9}$ - et d'une équipe 
d'une soixantaine de photoreporters, volontiers mise en lumière, comme lors de la publication d'un « portrait de famille » dans un numéro de l'été 1960.

Fig. 3.

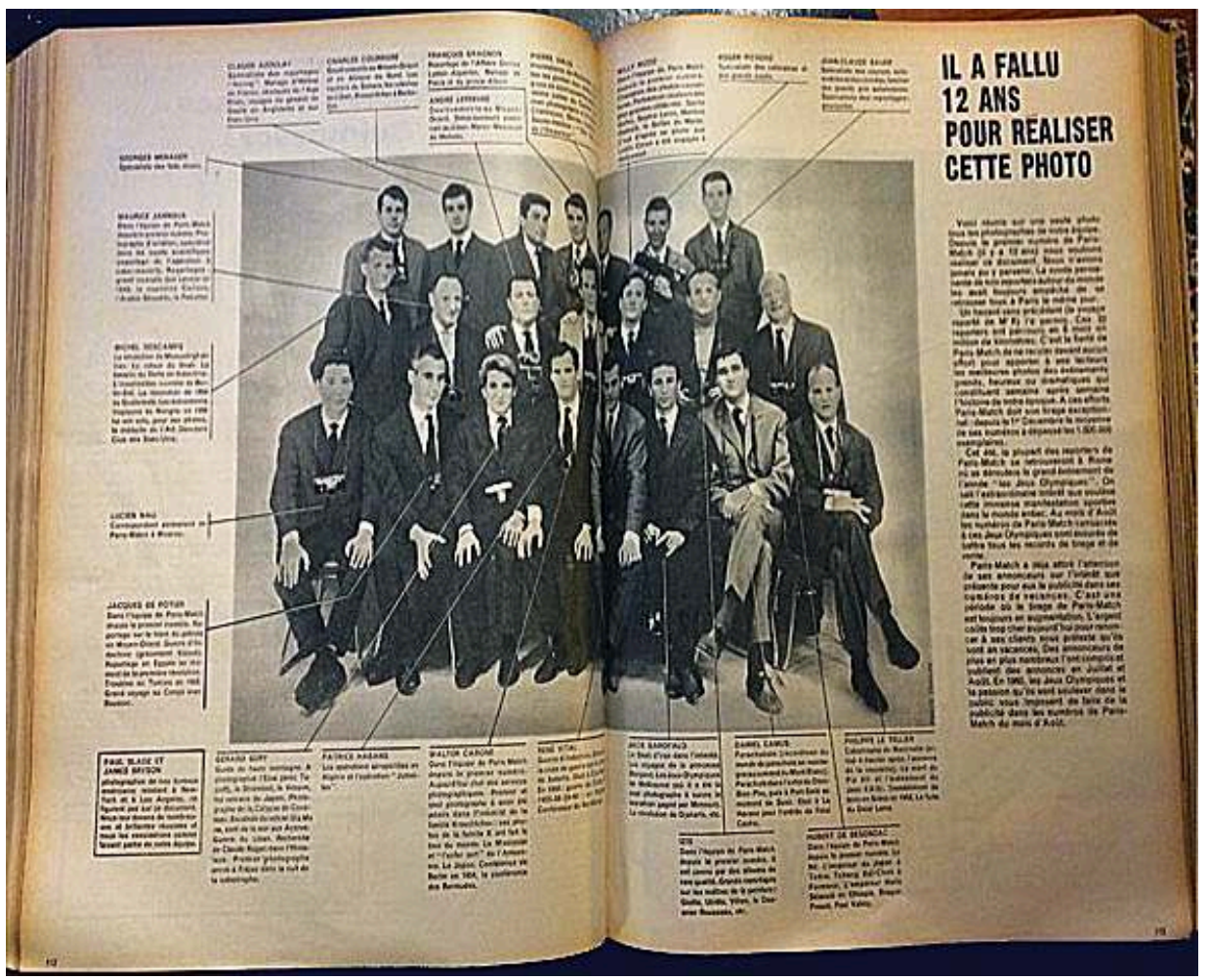

Paris Match, $n^{\circ} 582,4$ juin 1960

(C) D.R.

Pour être au cœur de l'actualité et couvrir les «évènements " d'Algérie, selon les termes employés à l'époque par les autorités françaises, une équipe de vingt et un photoreporters est déployée. Ces derniers sont habitués aux situations extrêmes et aux terrains. Sur les vingt et un, six seront appelés en Algérie : bien que réformé, Claude Azoulay y fait son service militaire; Patrice Habans est appelé 33 mois parmi les parachutistes du $3^{\mathrm{e}}$ Régiment de Chasseurs Parachutistes (il réalise deux reportages : sur les opérations aéroportées en mai 1956 et sur l'opération "Jumelles" en août 1959); Jean-Claude Sauer se retrouve également chez les parachutistes durant deux ans de service militaire; Jean Tesseyre part pour l'Algérie en 1962 et travaille pour le magazine des armées ; Izis Bidermanas rejoint la légion à Sidi Bel Abbès et Jean Tassouan, les commandos Delta de l'OAS.

Quatre d'entre eux ont combattu en Indochine dont Daniel Camus qui s'engage chez les parachutistes à l'âge de 17 ans; Philippe Le Tellier est ancien militaire et Georges Ménager avait un père colonel. Tous ont un lien avec l'armée ou feront eux-mêmes la guerre. Ils bâtissent leur crédibilité sur le fait d'être au cœur de l'action et de l'information, rapportant ainsi des photographies saisissantes. La devise, « le poids des mots, le choc des photos ", est ainsi soigneusement appliquée.

13 La revue dispose, en outre, d'un bureau à Alger dans lequel Jean-Pierre Biot, photographe permanent de 1958 à 1961, est rejoint par des confrères parisiens pour les évènements importants ${ }^{10}$. Collaborant avec des journalistes sur place tels que René 
Sicart, contributeur à l'Écho d'Alger, ou Georges Melet, photographe de la Dépêche d'Algérie, Paris Match reste au plus proche de l'actualité algérienne ${ }^{11}$. Il défend la position officielle d'une Algérie française et adopte tout au long du conflit les prises de positions de l'exécutif français, en particulier lors de l'arrivée du général de Gaulle au pouvoir en 1958, qu'il défend de manière inconditionnelle.

\section{« En Algérie, la France ne fait pas la guerre, mais la police »}

Ce titre est tiré du no 294 (du 13 au 20 novembre 1954).

15 Bien que tous les moyens soient mis en place pour couvrir le confit algérien, la discordance entre la France et son ancienne colonie est telle que la question algérienne est reléguée à un rang secondaire dans l'opinion publique française ${ }^{12}$. Du moins, jusqu'en 1960, année durant laquelle le procès du réseau Jeanson contribue à donner une dimension nationale au conflit. Toute une génération, notamment celle née dans les années 1930, va être plongée dans une guerre où la pratique de la torture est systématisée, les confrontant ainsi à des questions morales épineuses. Et malgré l'envoi de plus en plus massif du contingent en Algérie à partir de 1955, la Guerre froide entre les États-Unis et l'Union soviétique et la menace atomique dominent les préoccupations des Français.

16 L'ordre du monde ainsi constitué, l'adhésion à la colonisation allait de soi et était amplement majoritaire ${ }^{13}$. Nées sous un régime colonial, des générations successives de Français pensent que «l'Algérie, c'est la France ». Les revendications nationalistes des Algériens sont incomprises ou éludées. C'est dans ce contexte que Paris Match tient la chronique du conflit. Que donne-t-il donc à voir ?

$17 \mathrm{Au}$ fil des numéros, le décalage entre la France et l'Algérie est flagrant. Dans le numéro 293, du 6 au 13 novembre 1954, le journaliste, Jean Farran, rapporte le déroulement des événements ; la guerre débute, pour lui, à la frontière tunisienne et est donc commandée de l'extérieur. Plus loin, les titres nomment la source de cette menace: «Dernier venu sous l'étendard vert: le terrorisme algérien », «l'étendard vert » faisant référence ici à l'Islam. Pour illustrer l'article, le lecteur est confronté à la photographie d'un militaire pointant son arme sur un prisonnier, qu'il tient enchaîné par une corde, tel un animal, au cou et aux poignets (fig. 4). 
Fig. 4.
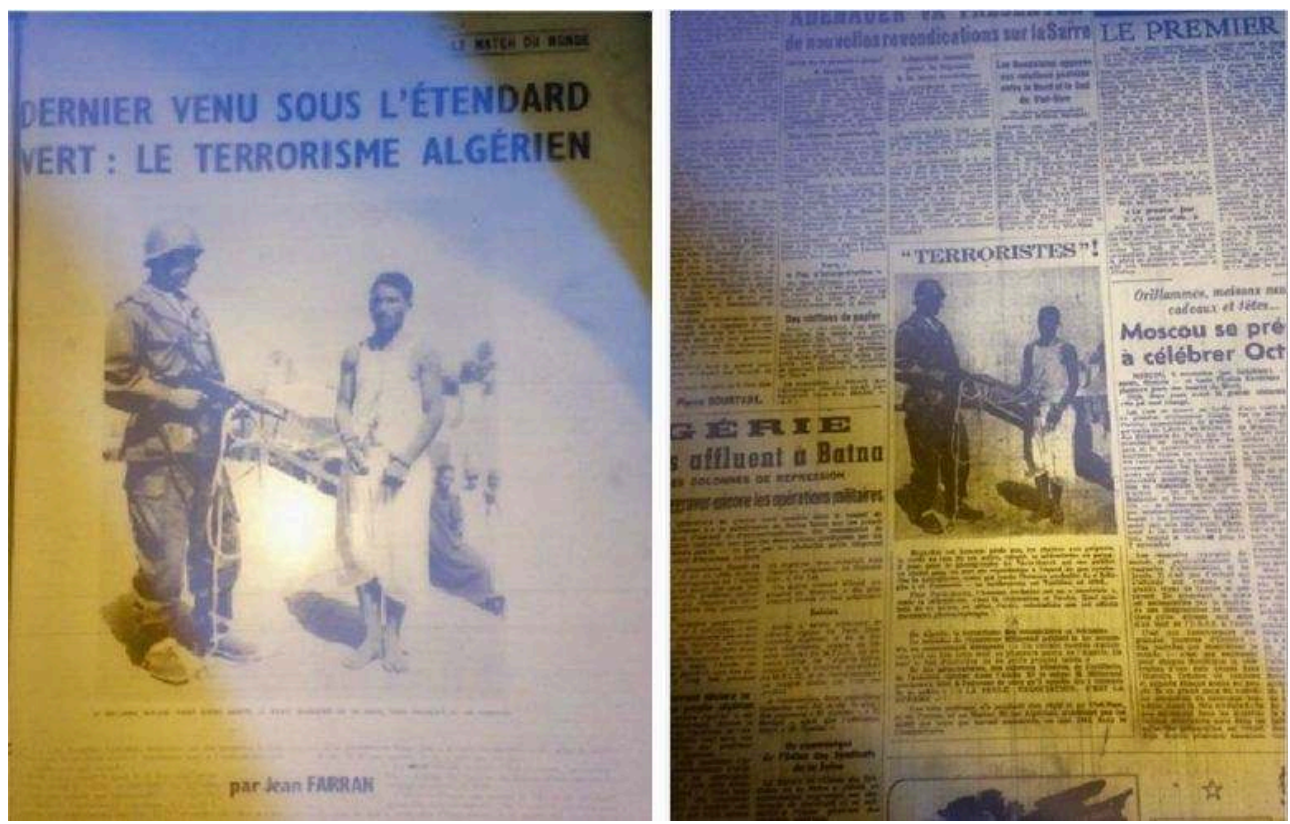

Paris Match, n² 293, du 6 au 13 novembre 1954 et L'Humanité, 6 novembre 1954.

(c) D.R.

Cette photographie rejoue l'iconographie esclavagiste du XIXe. Elle est d'autant plus choquante que l'homme enchaîné paraît être un simple paysan ou civil algérien. Sans autre preuve, la légende accompagnant la photographie déclare: «Le fellagha Djilani vient d'être arrêté. Il avait massacré de sa main trois Français et un Tunisien.» Illustrant les divisions idéologiques, cette photographie suscite déjà des commentaires à l'époque. Elle est également publiée par le journal L'Humanité le 6 novembre 1954 avec une toute autre légende ${ }^{14}:$ «Regardez cet homme pieds nus, les chaînes aux poignets, la corde au cou. Et cet autre casqué, la mitraillette au point; il pose pour le photographe de Paris Match qui ose publier ce cliché sans un mot de réprobation à l'égard de ce que symbolise la mitraillette mais qui traite l'homme enchaîné de "fellagha " et d'assassin - le malheureux est tunisien en effet... Pour Paris Match l'homme enchaîné est un "terroriste", mais la mitraillette c'est la civilisation et l'ordre. Quel symbole de ce qu'est, en effet, l'ordre colonialiste que cet odieux document photographique ${ }^{15}$ ».

Tout en dénonçant la propagande de Paris Match, le journal communiste applique la sienne, en s'arrêtant par exemple sur le symbole de la mitraillette plutôt que sur les chaînes au cou et aux poignets du prisonnier.

De la même façon, en 1955, le photographe Charles Courrière montre un prisonnier ligoté, au sol, devant un militaire, debout, arme au repos ${ }^{16}$. 
Fig. 5.

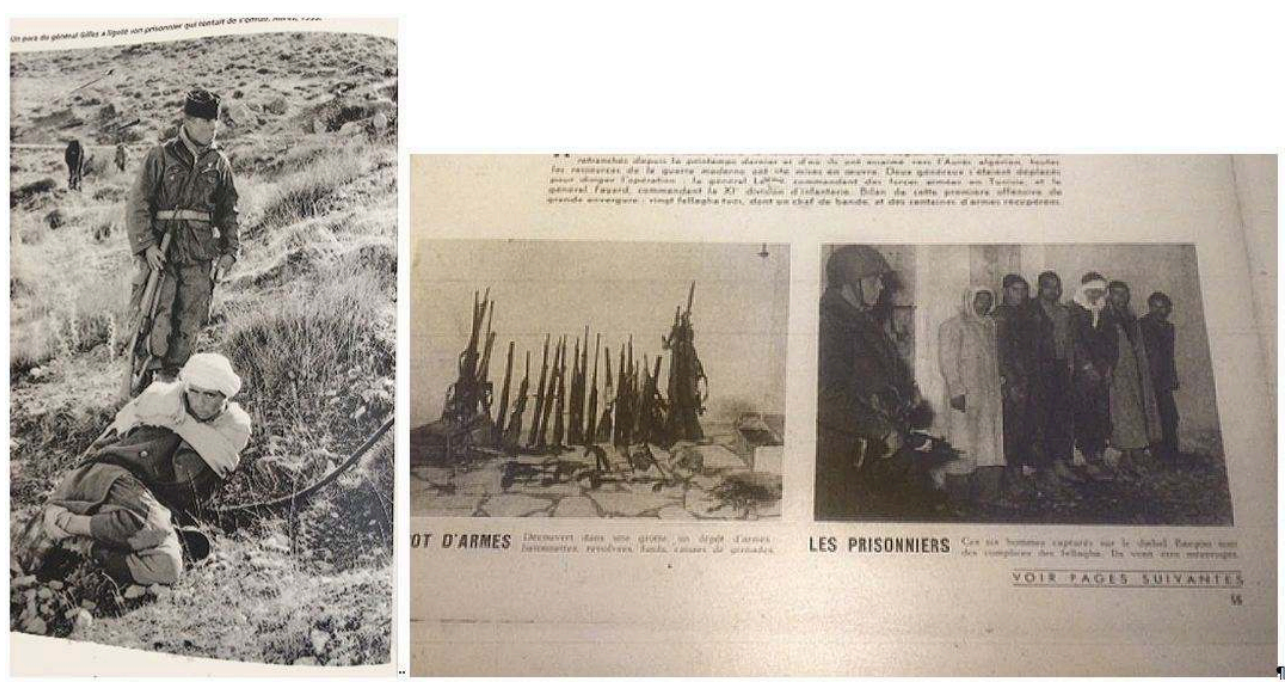

Charles Courrière, Aurès, 1955, et Paris Match, n² 295, du 20 au 27 novembre 1954.

(C) D.R.

19 Le numéro 370 du 12 mai 1956 montre un prisonnier les mains derrière le dos à terre entouré par deux militaires et un autre « combattant du FLN ». Dans le numéro 295 du 20 au 27 novembre 1954, un militaire tient en joue six « prisonniers » adossés à un mur.

La figure du prisonnier semble incarner l'archétype d'une iconographie de la soumission développée par le magazine tout au long du conflit pour représenter les Algériens.

Le journaliste propose ainsi principalement une analyse religieuse et géopolitique du début du conflit précisant: "Écartelé en 35 États et 350 millions d'hommes, l'Islam demeure uni par les 400 pages du Coran ». Il n'est donc pas hasardeux que le reportage suivant traite de l'Égypte de Nasser. Croyant à une "nation arabe » unie par l'Islam, Jean Farran présente l'Algérie comme commandée par Nasser et par les communistes. Jusqu'en 1955, elle est examinée en lien et comme une composante des " pays arabes ». La question algérienne est ainsi inscrite dans une analyse plus globale, parfaitement illustrée par la Une du numéro 336. 
Fig. 6.

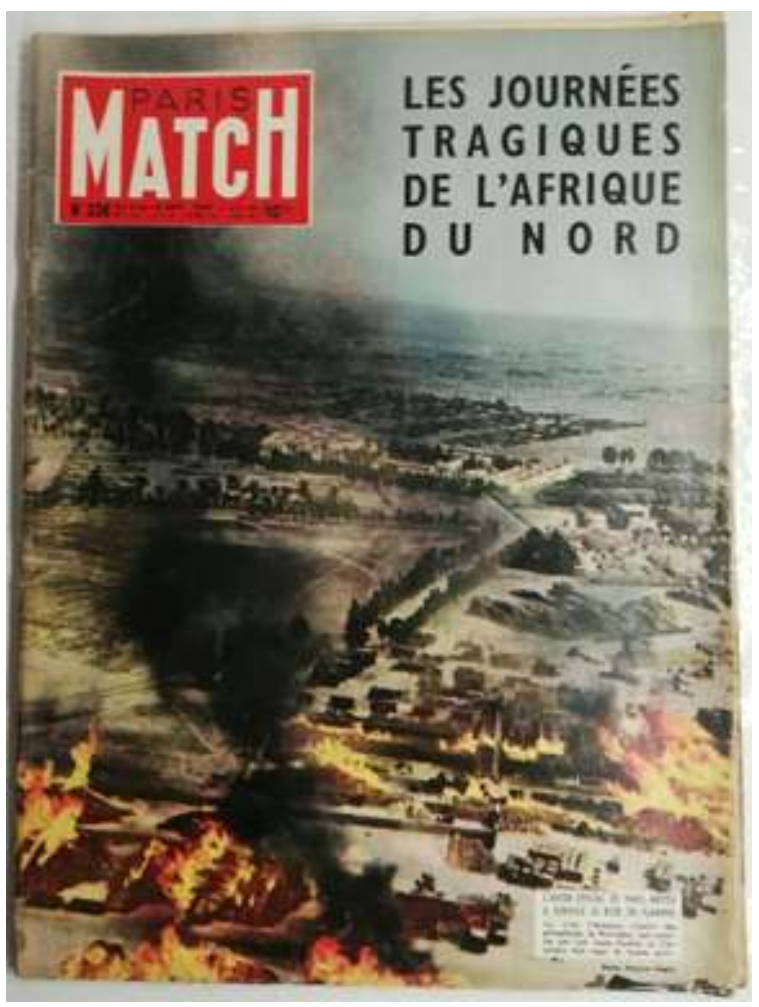

Paris Match, $n^{\circ}$ 336, du 3 au 10 septembre 1955.

(C) D.R.

Jean Farran revient néanmoins sur les luttes indépendantistes d'avant novembre 1954 et, à cette occasion, un portrait de Messali Hadj ${ }^{17}$ est reproduit ${ }^{18}$.

21 Durant l'année 1954, le ton alarmiste contraste avec des images finalement anecdotiques, du moins, sans grand intérêt informatif. Le lecteur y découvre de larges paysages envahis par les militaires. Dans le numéro suivant du 13 au 20 novembre 1954, en Une, l'annonce « nos envoyés spéciaux dans le maquis de l'Aurès » côtoie la nouvelle de la mort de Matisse, immortalisé par une photographie le montrant dans son atelier en train de peindre. 
Fig. 7.

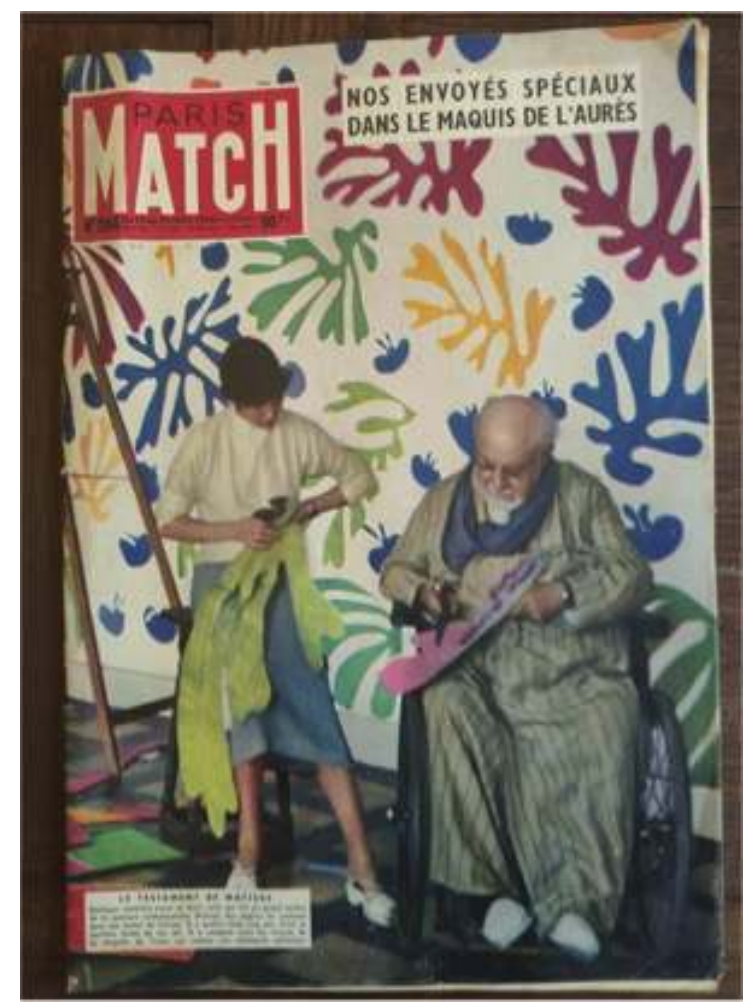

Paris Match, n² 294, du 13 au 20 novembre 1954. (C) D.R.

L'article consacré à l'actualité algérienne est titré « La Toussaint rouge d'Algérie a fait sortir de l'ombre 3000 hors-la-loi en uniforme ». L'auteur n'est autre qu'Armand Gatti. Personnage pivot, il connaît bien les milieux culturels parisiens et algérois. Il raconte ici l'exécution du «caïd Sadok » et d'un couple d'instituteurs, les Monnerot, dont on apprend que l'épouse survit à l'attaque. Après avoir détaillé l'horrible exécution du caïd et de Guy Monnerot, il retranscrit l'arrivée de la nouvelle en métropole. Il déclare en fin d'article, contrairement au discours officiel, que « les services de renseignements de la police et de l'armée précédaient et suivaient mesures d'urgence et de mise en place qui donnent à ces opérations policières l'aspect théâtral d'une guerre de reconquête, et à ces images de guerre, des premiers plans de chasse à l'homme ».

\section{La diffusion d'un discours de domination}

En effet, en image, la guerre n'est présente qu'à travers le déploiement sur un vaste terrain des militaires et de l'armée française. Les photoreporters rejouent ici l'idée d'une guérilla où l'ennemi est pourchassé, insaisissable et invisible. Dans le numéro 295, dix jours seulement après le déclenchement de la guerre, les images sur le conflit montrent l'armée française en pleine maîtrise du terrain. Les titres vont également dans ce sens: «En Algérie, paras et blindés traquent le nouveau terrorisme »; "Contre les fellagha, l'armée prend l'offensive ». Dès le début du conflit, Paris Match met en place une iconographie particulièrement manichéenne. Il joue des antagonismes autant du point de vue sémantique qu'iconographique. Il défend en outre une véritable idéologie militariste, magnifiant le rôle de l'armée et des militaires, en 
particulier l'élite militaire française, les gradés, les légionnaires et les parachutistes, invariablement montrés en position de héros, secourant les blessés et servant courageusement le pays ${ }^{19}$.

Fig. 8.
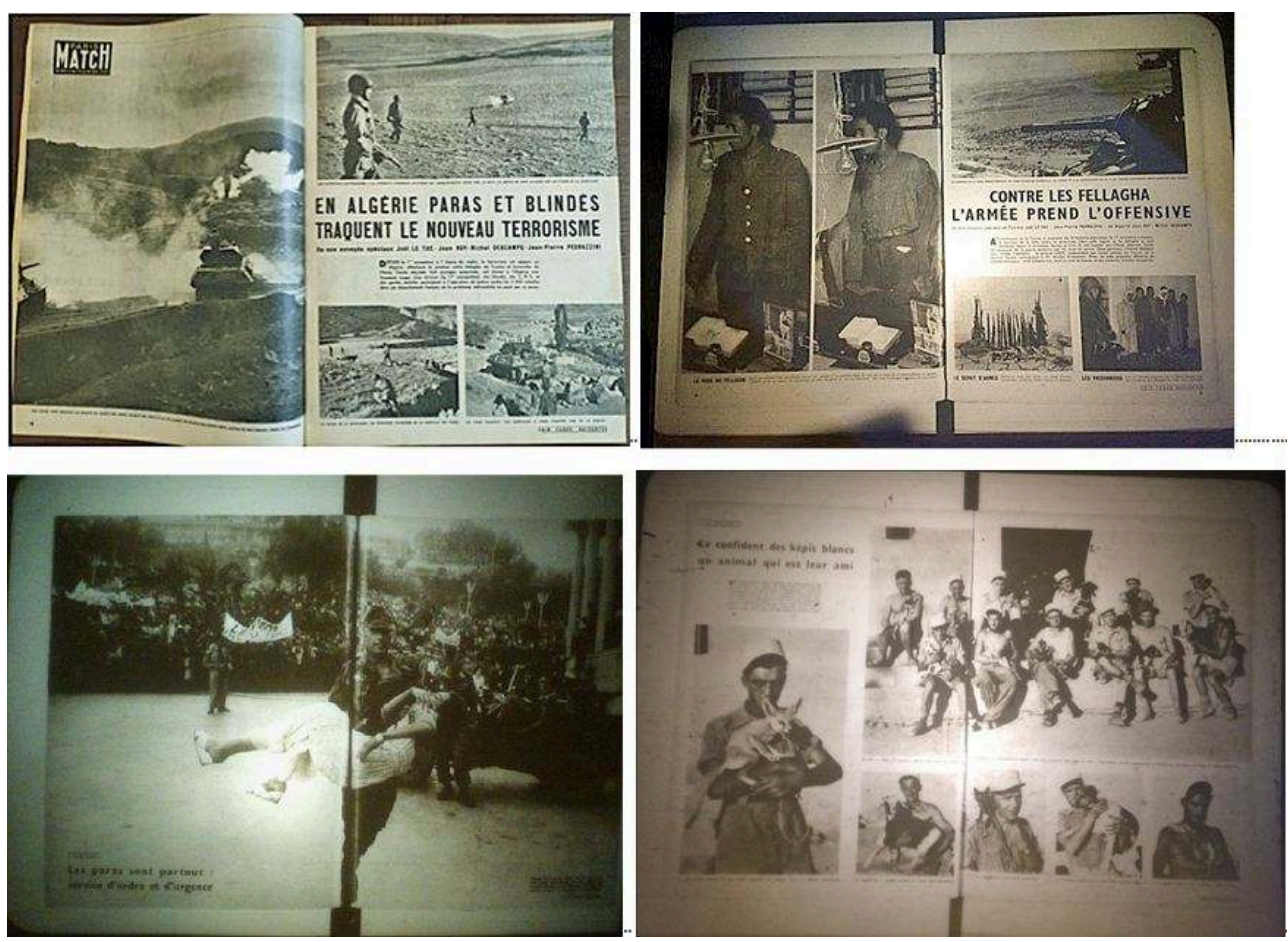

Paris Match, $n^{\circ}$ 294, du 13 au 20 novembre 1954 (C) D.R.

24 L'armée française est ainsi montrée se déployant à la frontière tunisienne, sur le territoire algérien, en totale possession du terrain. Le magazine dessine deux camps: d'un côté, les « hommes léopards » représentés dans le feu du déploiement, de l'action, forts et servant héroïquement la patrie, face à une "force obscure ", «invisible » et «mystérieuse ». Les qualificatifs se déclinent à souhait pour nommer les combattants algériens: «fantômes", « ennemis », "fellagha », «hors-la-loi », « rebelles» ou «terroristes».

Au fil des numéros, les légionnaires et les parachutistes sont montrés en position de sauveurs, quand ils ne sont pas humanisés par des scènes de vie quotidienne et de répit ${ }^{20}$.

En face, soumis à la force militaire française, le fellagha est qualifié de «fourbe » ou «violent». Invisible, il n'a pas de visage, il est «mystérieux et dangereux ${ }^{21}$. Ou lorsqu'il en a un, il est menaçant ou enchaîné, maîtrisé et fait prisonnier. 
Fig. 9.
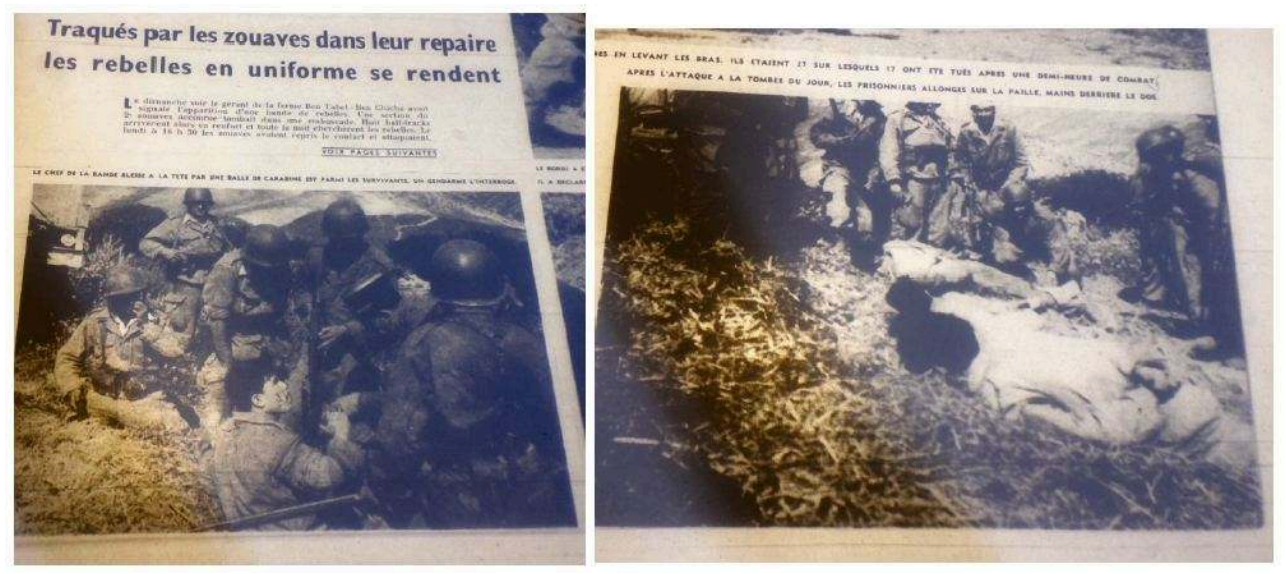

Paris Match, $n^{\circ} 371,19$ mai 1956.

(C) D.R.

Faisant fi du contexte réel, ces images sont d'autant plus douteuses qu'elles montrent quelquefois de simples civils algériens. Il s'agit pour le magazine d'affirmer, ou plutôt de réaffirmer, la position dominante de la France, et de montrer ainsi aux citoyens métropolitains que la situation est sous contrôle. Pour cela, il multiplie les titres sur une supposée reddition des combattants algériens : "Au pied de l'Aurès un rebelle se rend ${ }^{22}$ "; «Aux confins tunisiens un commando $\mathrm{FLN}^{23}$ qui cherchait à fuir s'est rendu sans combat ${ }^{24}$ ", et montre «l'ennemi » pénitent et prosterné face à une puissance militaire charitable : « Dix mille rebelles au rendez-vous du pardon ${ }^{25}$. »

Fig. 10.
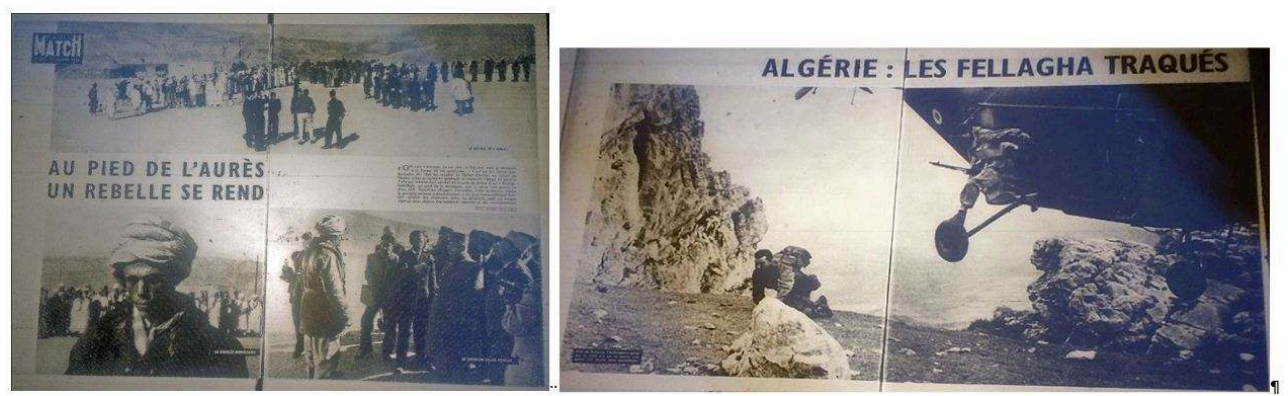

Paris Match, n³52, 7 janvier 1956, et n³70, 12 mai 1956.

(C) D.R.

Les combattants algériens sont animalisés, dans une " chasse » où ils sont " traqués »: «L'ennemi est chassé du verger à la grenade ${ }^{26}$ »; «Algérie : les fellagha traqués ${ }^{27}$ »; "Traqués par les zouaves dans leur repaire les rebelles en uniforme se rendent ${ }^{28}$ ". Captifs, apeurés ou ensanglantés ${ }^{29}$, ils peuvent aussi avoir l'air hébété, fraternisant avec le colon ou le militaire bienfaisants. L'iconographie de la soumission se décline ainsi à souhait.

Par ailleurs, pour appuyer l'idée que le FLN tient en otage la population musulmane, et qu'ils sont minoritaires, la revue prend soin d'appliquer une distinction iconographique entre «fellagha » et population " musulmane ». Cette dernière est représentée dans des scènes de fraternisation au contact des Français ${ }^{30}$. Dans le numéro du 31 mars 1956, le 
lecteur suit "l'aventure du transalgérien » où "voyageurs en képi et voyageurs en djellabah dorment côte à côte $»^{31}$. La population musulmane apparaît massive, le plus souvent en groupe, en vêtements traditionnels, démunie et l'air hébété lors de fouilles ou de quadrillage ${ }^{32}$.

Fig. 11.
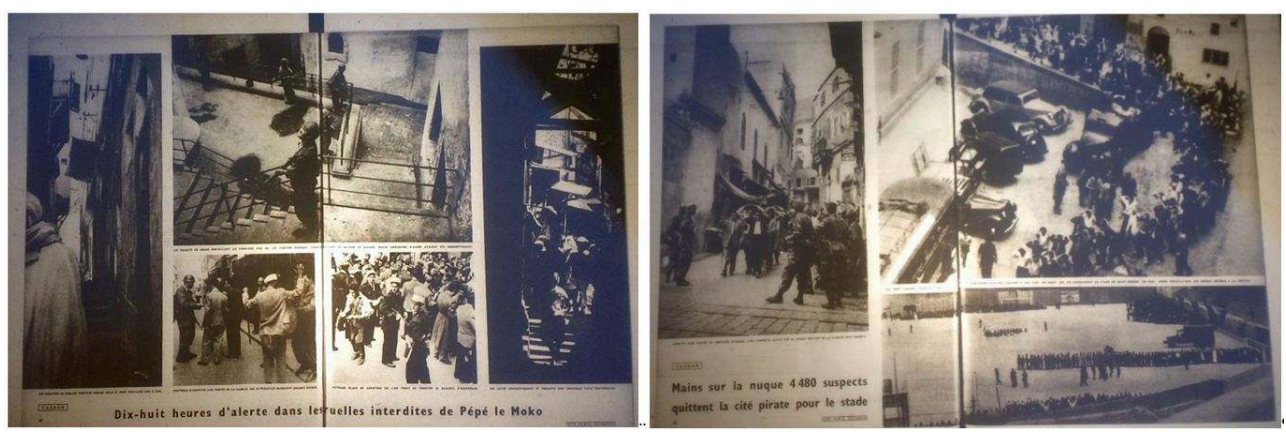

Paris Match, $n^{\circ} 374$, et ndu 9 juin 1956

(c) D.R.

L'idée de la «France civilisatrice » est accentuée. Les combattants du FLN sont quant à eux quasiment anonymes ou représentés en guerriers fourbes, captifs, maitrisés par des militaires ${ }^{33}$. Seuls les leaders des mouvements indépendantistes bénéficient de véritables portraits, en pied, le regard défiant le photographe pour Yacef Saadi ${ }^{34}$ lors de son arrestation en $1957^{35}$ (fig. 12A). Messali Hadj a droit à son portrait au début de la guerre ${ }^{36}$ et un reportage de quatre pages lui est consacré en janvier $1959^{37}$. Ahmed Ben Bella $^{38}$ apparaît dans le numéro 395 au moment du détournement de l'avion des chefs du FLN ${ }^{39}$ et lors des négociations en $1961^{40}$. En mai 1961, il est aux côtés de Mohammed Khider $^{41}$ et Hocine Ait Ahmed ${ }^{42}$.

De manière insolite, le vice-président du Gouvernement provisoire de la République Algérienne ${ }^{43}$, Krim Belkacem ${ }^{44}$, est photographié à la descente d'un hélicoptère, luttant contre le vent. Il réapparaît en chef politique deux semaines après ${ }^{45}$ (fig. 12B).

La dépouille d'Amirouche ${ }^{46}$, colonel de l'armée de libération nationale, commandant de la wilaya III (Kabylie) est exhibé en arrière-plan d'une photographie dans le numéro 522 du 11 avril $1959^{47}$ (fig. 12C).

Ferhat Abbas ${ }^{48}$ quant à lui apparaît dans le numéro 637 du 24 juin 1961 dans la rubrique «ces hommes qui font l'événement» avec un portrait de profil peu flatteur et grimaçant (fig. 12D). 
Fig. 12.
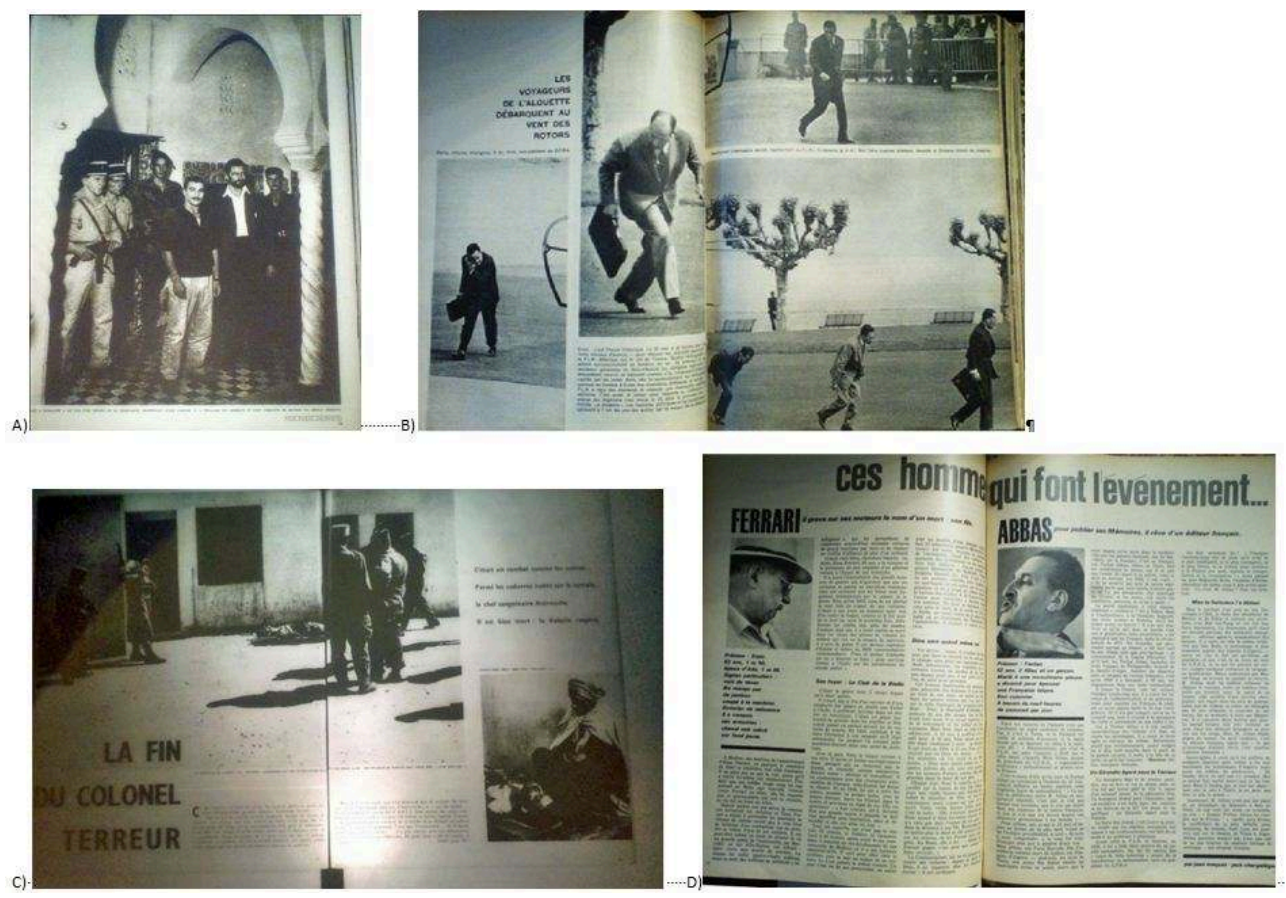

A) Yacef Saadi, Paris Match, n 443, 5 octobre 1957. B) Krim Belkacem, Paris Match, n 634, 3 juin 1961. C) Paris Match, $n^{\circ}$ 522, 11 avril 1959. D) Ferhat Abbas, Paris Match, $n^{\circ}$ 637, 24 juin 1961.

(C) D.R.

Benyoucef Benkhedda ${ }^{49}$, nouveau président du GPRA, occupe la même rubrique, avec un portrait confiant et mystérieux, vêtu d'un costume et de lunettes de soleil, quelques mois après ${ }^{50}$.

Ces leaders politiques sont tantôt photographiés comme des chefs militaires dangereux ou tantôt surpris dans des expressions ou des positions cocasses et/ou peu flatteuses, au même titre que des vedettes.

Dans le numéro 295, du 20 au 27 novembre 1954 (fig. 13), au début de la guerre, l'un des premiers reportages porte sur « l'offensive de l'armée contre les fellagha ». Il prend la forme du roman-photo, créant des personnages stéréotypés. Les lecteurs sont invités à suivre, de manière artificielle, une opération supposée : nous parcourons des vignettes sur « les prisonniers », six personnes sont alignées et gardées par un militaire, « la ruse du fellagha ", double photographie dans laquelle nous voyons un jeune homme portant une veste de combat puis sans sa veste, qu'il enlève derrière un minuscule bureau. La légende déclare: "sous son uniforme kaki, un fellagha portait une chemise et un pantalon bleus. Il n'eut pas le temps de se métamorphoser en paisible Tunisien avant sa capture. Les gendarmes ont ainsi découvert la ruse des hors-la-loi : faire peau neuve pour échapper aux poursuites ${ }^{51}$. "

Le mouvement est autant que possible privilégié, de sorte à créer l'illusion d'une participation à l'action. Nous sommes ainsi plongés dans «la formation de combat », dans « l'opération ratissage », la « réunion au Q.G. », « la messe des armées » etc. 
Fig. 13.

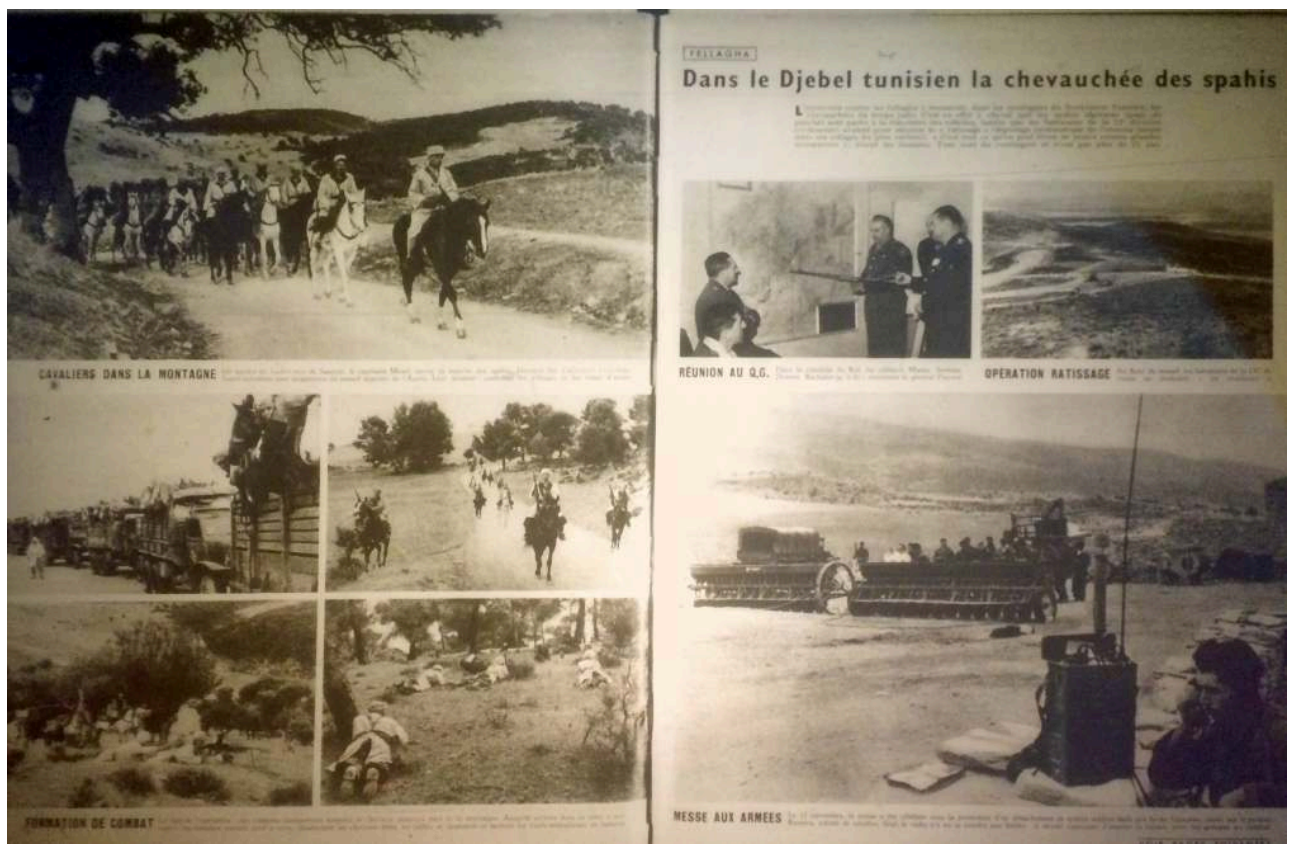

Paris Match, n²95, du 20 au 27 novembre 1954.

(C) D.R.

31 En 1955, l'actualité algérienne est peu présente mais le magazine prend soin de rapporter sur sept pages la conférence de Bandoeng où, selon le journaliste, « 29 nations d'Afrique et d'Asie mettent l'homme blanc en accusation ${ }^{52}$ ", et les massacres $\mathrm{du}$ Constantinois en août ${ }^{53}$. Sur une carte géographique, l'Algérie est représentée comme pays non participant alors que la conférence des non-alignés reçoit une délégation du FLN. Les interventions de Benyoucef et Taïeb Slim, représentant du néoDestour sont toutefois retranscrites dans l'article. La revue rapporte l'accusation des indépendantistes : "Soudain, Taïeb Slim lança sa bombe : il déclara avec émotion que "la terreur de la Gestapo pendant la guerre n'était rien comparée aux tortures et aux arrestations faites par la France en Afrique du Nord". ${ }^{54}$ " Un journaliste anglais les interroge alors sur cette comparaison et la présence de camps de concentration. Benyoucef, visiblement mécontent de la question, l'invite à sortir. "Les obsèques de Philippeville $»^{55}$ sont quant à elles rapportées avec dignité, montrant les innombrables cercueils enveloppés de drapeaux français et fleuris, ainsi que la foule venue rendre hommage aux victimes. 
Fig. 14.

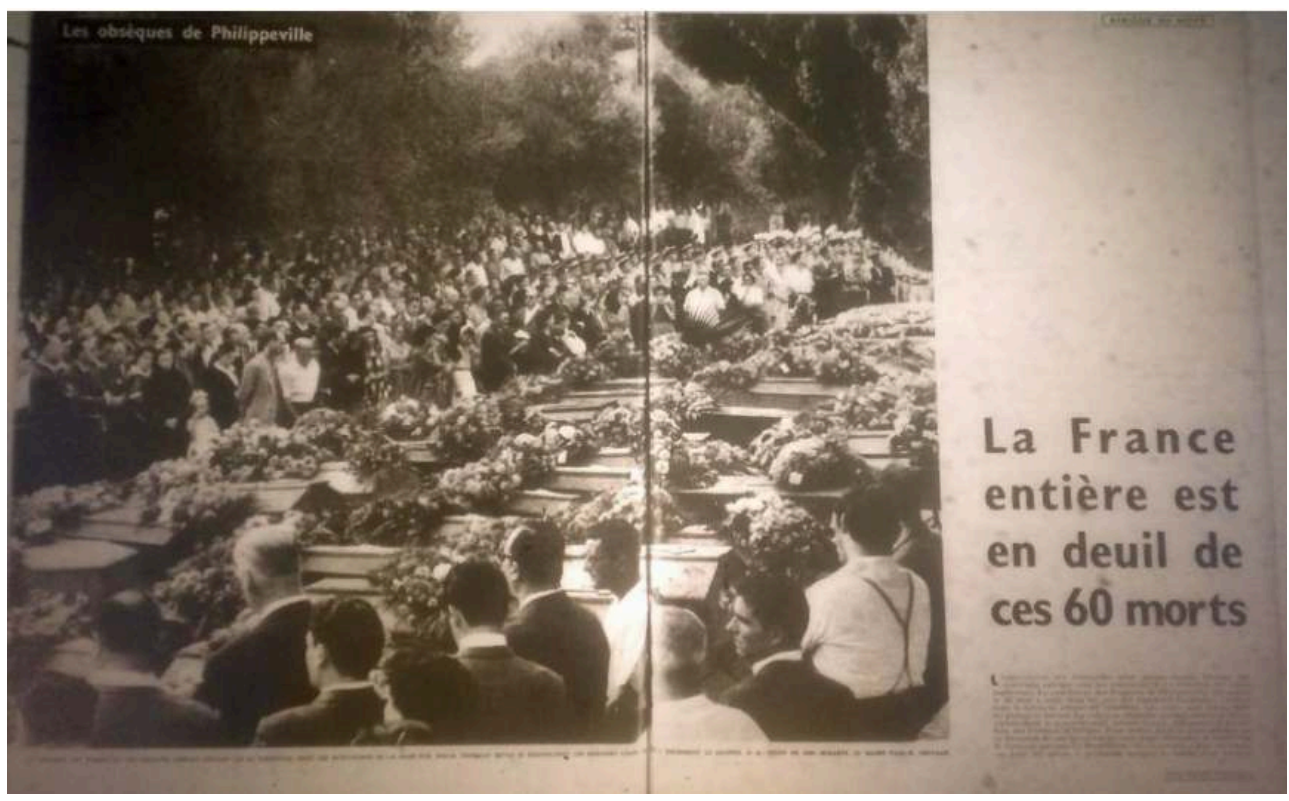

Paris Match, n³36, du 3 au 10 septembre 1955.

(C) D.R.

32 À partir de 1956, le sujet est de plus en plus présent et la guerre n'est plus niée; les rédacteurs parlent d'une " réalité ignorée », de "guerre » et "d'insécurité » pour une partie des «Français». Dans le numéro 353 du 14 janvier 1956, le journaliste Jean Farran parle, malgré « les pudeurs officielles », d'un « état de guerre ». De là, la revue prend position en faveur des Européens d'Algérie et «le désespoir des Français d'Algérie » est régulièrement rapporté. Il dessine des camps bien distincts; les titres opposent «l'armée de fantômes » aux « 950000 Français d'Algérie » qui disent : «la métropole nous a trahis ». C'est d'ailleurs la première actualité à apparaître en Une du magazine. La "journée des tomates » ${ }^{56}$ est annoncée dans le numéro 358 du 18 février 1956 par le titre de " Tumulte à Alger » et par une photographie d'une scène d'émeute, montrant une masse de policiers échappant à une énorme fumée. 
Fig. 15.

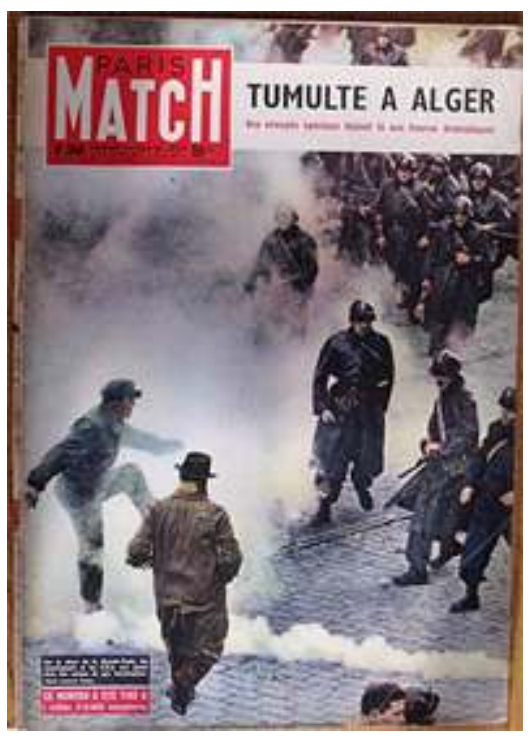

Paris Match, n³58, 18 février 1956

(C) D.R.

Au lendemain du vote des pouvoirs spéciaux, le 13 mars 1956, la Une de couverture de Paris Match avertit: "Sur le sol algérien, la patrie engagée». La photographie qui l'accompagne est un portrait en pied d'un chasseur alpin dans les montagnes de Kabylie. Les « diables blancs » sont alors suivis par les photoreporters de Paris Match et le «drame algérien » est développé sur seize pages ${ }^{57}$. Les rappelés ne semblent pas être une préoccupation centrale du magazine et n'arrivent que dans le numéro 369 du 5 mai 1956, dans lequel les reporters documentent le départ du « contingent 53-1 ». Quelques pages plus loin, la revue rapporte que "l'Algérie soulève à Paris, salle Wagram où Claude Bourdet doit intervenir, une tempête de chaises" entre "partisans et adversaires de la répression ». Engagé à gauche, ancien résistant, compagnon de la libération, Claude Bourdet est très engagé sur la question des appelés. Il est arrêté en mars 1956 suite à un article intitulé "Pas de contingent dans votre guerre » dans France-Observateur. Il est également très actif sur la question des tortures, qu'il dénonce très tôt dans les colonies françaises et en Algérie à partir de 1955, publiant un article intitulé « Votre gestapo d'Algérie » dans France observateur du 13 janvier 1955.

Les rappelés sont ensuite montrés dans le numéro 372 du 26 juin 1956 en héros « acclamés à Philippeville» (fig. 16A), puis le mois suivant en «messagers de la paix » proches de la population et intégrés à l'armée ${ }^{58}$. Nous les retrouvons en mai 1961 après le putsch des généraux dans le numéro 631 du 13 mai 1961 dans lequel leur loyauté au général De Gaulle est saluée ${ }^{59}$ (fig. 16B). 
Fig. 16.

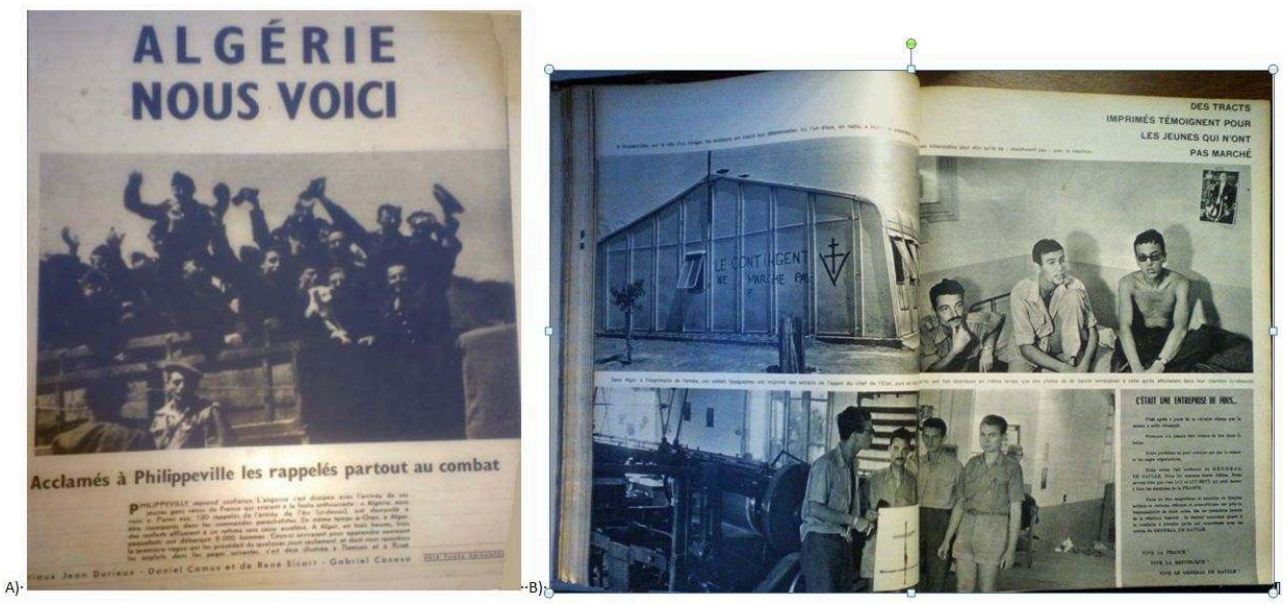

A) Paris Match, $n^{\circ} 372$ du 26 juin 1956. B) n 631, 13 mai 1961.

(C) D.R.

En revanche, l'embuscade de Palestro émeut la France. La section, composée uniquement d'appelés du contingent et commandée par le sous-lieutenant Hervé Artur, est massacrée par le FLN le 18 mai 1956. Pierre Dumas est le seul survivant. Paris Match y consacre une dizaine de pages dans le numéro 373 du 2 juin $1956^{60}$ (fig. 17A). Il illustre en photographies leur départ de Marseille et affiche en pleine page le portrait ensanglanté de Pierre Dumas, seul rescapé.

Fig. 17.
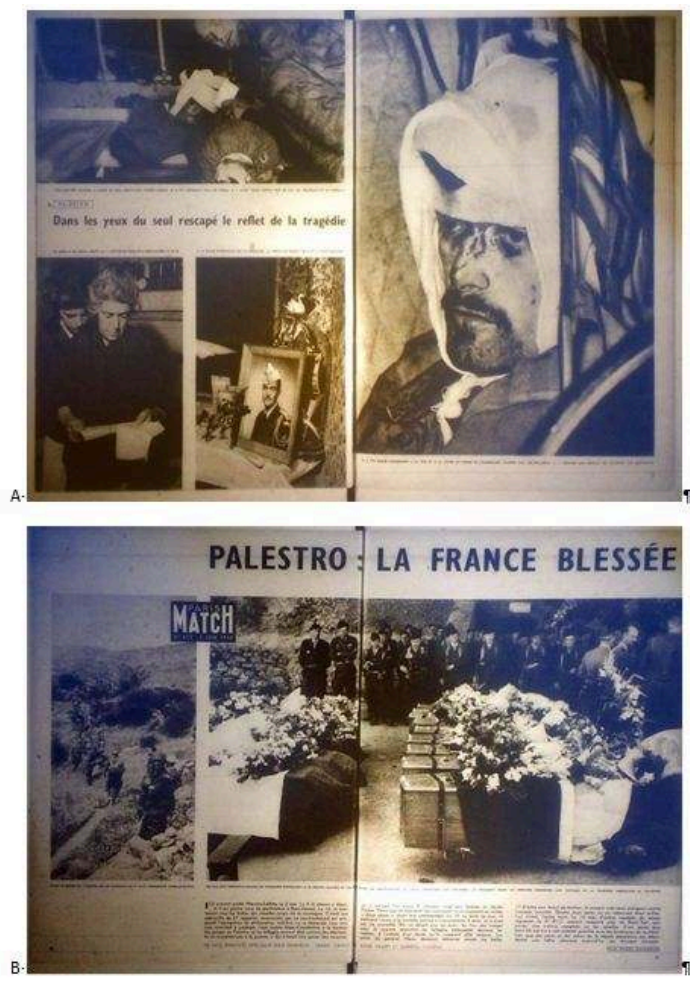

A) Paris Match, n³73, 2 juin 1956. B) n³73, 2 juin 1956 (C) D.R. 


\section{Les intérêts de la France en jeu}

La fin de l'été 1956 est consacrée à l'actualité internationale, principalement à la crise de Suez et, en fin d'année, à l'insurrection de Budapest. Bien que celle-ci soit centrale, la revue accorde six pages à la « capture en plein ciel» des « 5 chefs fellagha » dans le numéro du 3 novembre 1956. Une photographie de Ben Bella, Khider, Boudiaf, Lacheraf et Ait Ahmed ${ }^{61}$ autour de Moulay Hassan, prince du Maroc est affichée ${ }^{62}$. Éludant les conséquences diplomatiques, il célèbre le fait que "la rébellion a dû livrer tous ses secrets $»^{63}$. Chacun des chefs a droit à son propre portrait et la revue assure qu'ils « sont courtoisement traités ", ce que le lecteur peut vérifier grâce au portrait en pied d'une magnifique hôtesse, Nicole Lambert, qui "occupa les passagers». La femme semble symboliser la réconciliation, incarner la paix. Si bien que lorsque des femmes sont représentées, elles sont associées aux termes de «fraternisation» et de "paix ». La revue en donne un exemple édifiant dans le numéro $683 \mathrm{du} 12$ mai 1962, dans lequel deux Européennes et une Algérienne en haïk se croisent, faisant "rêver de la paix » malgré la présence des chars à leurs côtés.

Fig. 18.

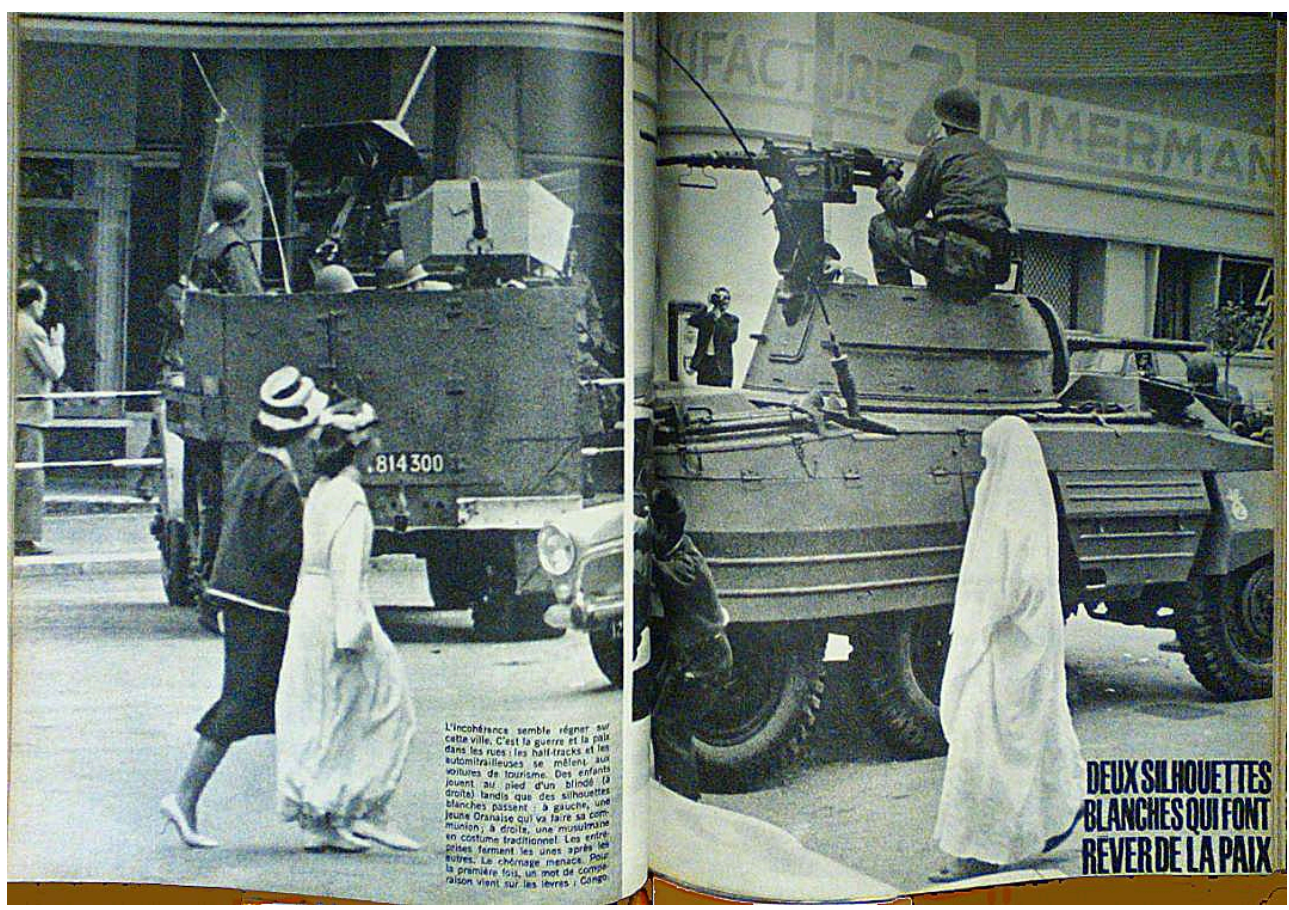

Paris Match, $n^{\circ}$ 683, 12 mai 1962.

(C) D.R.

En outre, à partir de 1956, au niveau national, la question du pétrole au Sahara est introduite. Plus la guerre s'enlise, plus elle devient cruciale, en particulier lors de l'arrivée du général De Gaulle au pouvoir en 1958. Les intérêts de la France en Algérie deviennent en effet essentiels lorsque la question algérienne secoue les institutions au sommet de l'État. Jusqu'en 1959, de nombreux reportages photographiques sont consacrés à « la bataille du grand sud » et à la « lutte pour le pétrole » ${ }^{64}$. Paris Match met en avant les infrastructures mises en place par la France pour exploiter le sol et les 
protéger. De l'extraction au convoi, tout y est arboré. La France est ainsi représentée en tant que puissance disposant des meilleurs moyens techniques et humains. Le lecteur découvre, une fois de plus, des images de militaires, explorant le désert sur d'énormes camions, en pleine possession des lieux. Ils parent aux dangers d'un environnement désertique et inhospitalier ou vont à la rencontre des locaux ${ }^{65}$. Nous suivons ainsi les « routiers du pétrole » et, là encore, la revue privilégie une sémantique de l'opposition ; une France apportant sa technologie et son savoir-faire est mise en concurrence avec une Algérie sous-développée et archaïque. Les photographies sont censées témoigner de " Deux époques (qui) se croisent sur la piste du pétrole : camions et chameaux ${ }^{66}$ ».

La revue rassure ses lecteurs sur la présence et le contrôle de l'« or noir » : «Sous cette gerbe de "brut" une nappe grande comme Paris » et « Du ciel et de la route on veille sur le convoi $»^{67}$.

Dans le numéro 451 du 30 novembre 1957, la revue rapporte «l'attaque de la colonne pétrole» par les «rebelles». Cette annonce s'accompagne d'une photographie somptueuse sur deux pages des dunes du Sahara ${ }^{68}$. Il assure que l'armée "vengera les douze morts». Puis dans un récit sur deux pages pleines, "les rescapés racontent l'embuscade du désert rouge ». Là encore, nous suivons, comme sous la forme du roman-photo, une dizaine de photographies sur «la grande aventure des prospecteurs" qu'ils auraient eux-mêmes prises avant l'attaque ${ }^{69}$. En Une du numéro 405 du 11 janvier 1958, un encart annonce que «Le PETROLE DU SAHARA COULE VERS LA FRANCE " accompagné d'un portrait du chef spirituel Karim Aga $\mathrm{Khan}^{70}$. Consciente que le contrôle sur le pétrole est un «capital d'énergie qui peut bouleverser l'économie de l'Europe ${ }^{71}$, la revue s'attache donc à rendre régulièrement compte de l'« histoire française du désert $»^{72}$.

\section{La question algérienne, une actualité internationale}

En somme, l'année 1956 marque un durcissement du conflit et les images de guerre et de domination française se multiplient. Par ailleurs, jusque-là, la question algérienne est traitée comme une question de politique intérieure. Or, elle devient retentissante au niveau international à partir de février 1957, durant la bataille d'Alger ${ }^{73}$. Paris donne les pleins pouvoirs au général Massu et la généralisation de la torture scandalise. L'opération est un succès militaire mais l'action de la France est discréditée au niveau international. Une résolution de l'ONU préconise, en outre, l'ouverture de pourparlers avec le FLN et contredit la compétence exclusive de la France dans le règlement de la guerre $^{74}$. Mais pour Paris Match le «drame algérien» n'acquiert sa dimension internationale qu'en février 1958, lors du bombardement du village tunisien, Sakiet Sidi Youssef $^{75}$. Une commission anglo-américaine de bons offices est alors imposée ${ }^{76}$.

Pour préserver l'image de la France, la revue persiste à montrer un pays sous contrôle. Dans le numéro du 19 janvier 1957, un long article de Jean Farran est consacré à la "l'opération Casbah qui annonce la reprise en main de la sécurité par les paras du général Massu ». Quatre photographies l'accompagnent où des policiers sillonnent la Casbah d'Alger, soumettant les Algériens à des contrôles et à des fouilles ${ }^{77}$. Le 9 février 1957, "la riposte de la Casbah» rapporte des images des attentats du FLN dans différents cafés de la ville et l'appel à la grève générale. La propagande de Paris Match est formelle lorsqu'il affirme que les «forces de l'ordre investissent la casbah pour protéger les musulmans qui veulent se rendre à leur travail» en légende d'une 
photographie de la population quadrillée ${ }^{78}$. Plus cocasse est la photographie d'une fanfare en plein Alger assaillie par des enfants venus récupérer des bonbons généreusement distribués ${ }^{79}$. Alors que la bataille d'Alger fait rage et que le pays est entaché par les scandales liés à la torture, ce choix de photographie accentue la propagande d'une France généreuse envers les innocents et la population civile. Le 9 mars 1957 « les paras de Massu» sont mis en scènes, triomphants ${ }^{80}$.

Le 16 février 1957, « l'affaire France à l'ONU » est narrée. Un face à face photographique est orchestré entre Christian Pineau, ministre des Affaires étrangères et $\mathrm{M}$. Zeineddine (Syrie). Les vignettes photographiques montrent les différents participants quand les légendes les font parler $^{81}$. La question algérienne est alors traitée du point de vue international même si la revue insiste sur la " propagande » de l'ONU et la maîtrise du terrain par les militaires. En outre, à partir de juin 1957, les crises gouvernementales font régulièrement l'actualité et l'arrivée du général de Gaulle en mai 1958 est accueillie avec ferveur. Elle fait la Une du numéro 477 du 31 mai 1958 dans lequel les photographies de fraternisation et d'euphorie se multiplient (fig. 19A). De Gaulle bénéficie de deux pages pleines apparaissant en pleine déclamation de son discours (fig. 19B).

Fig. 19.

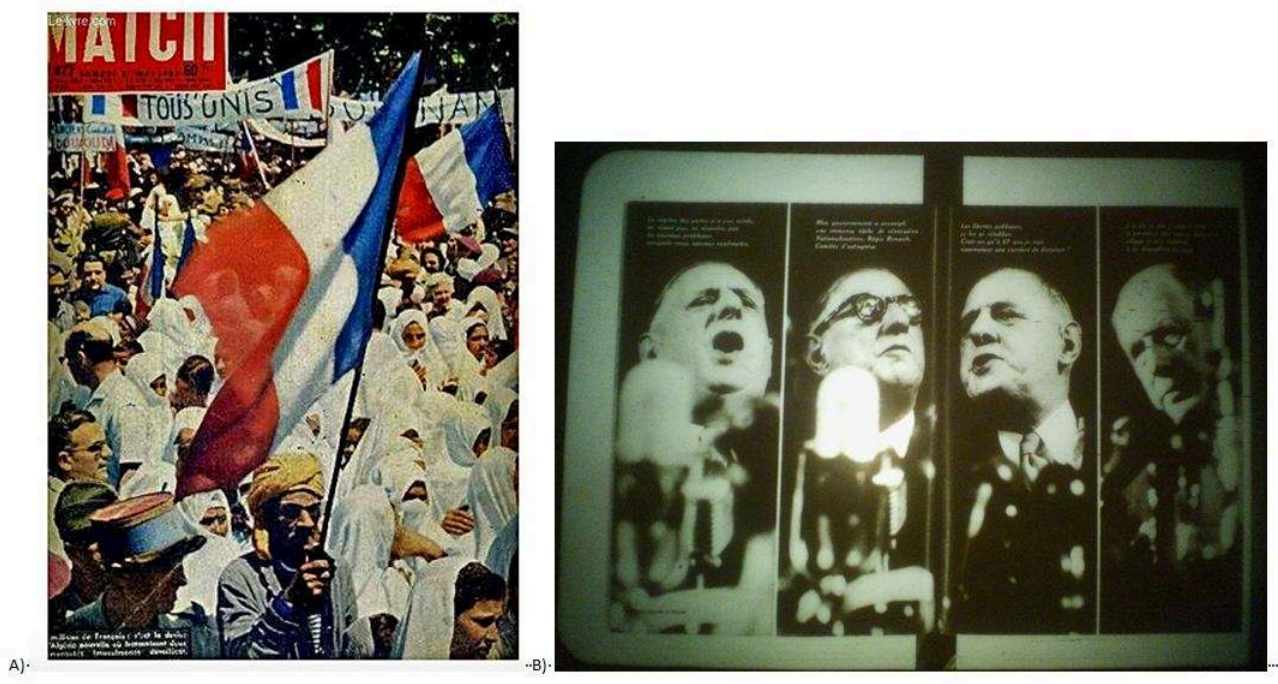

A) Paris Match, n 477, 31 mai 1958. B) n 477, 31 mai 1958.

(C) D.R.

Il devient très présent et fait régulièrement la Une du magazine; son arrivée à la tête du pays, ses voyages et ses visites en France et en Afrique sont documentés ${ }^{82}$. Il est suivi à Dakar, Abidjan, au Libéria, à Madagascar, au Congo, etc ${ }^{83}$. Les images où il est accueilli par une foule enthousiaste, et où $\mathrm{V}$ et croix de Lorraine sont arborés dominent. De nouvelles rubriques apparaissent - «la vie privée de la politique », «l'instantané de la semaine" - et sont prétextes à ériger De Gaulle en sauveur face à la question algérienne, en souverain et guide incontesté non pas seulement en France mais également dans le monde ${ }^{84}$. 


\section{0 : l'arrivée de la guerre en métropole}

43 L'année 1960 marque un tournant. Alors que le procès du réseau Jeanson, réseau français d'aide au FLN, s'ouvre au tribunal militaire de Paris le 5 septembre 1960, la population française de métropole découvre une dissidence de l'intérieur et prend véritablement conscience de la guerre en train de se mener. Profitant de ce contexte de visibilité, le lendemain, une déclaration sur le droit à l'insoumission dans la guerre d'Algérie dit Manifeste des 121 est publiée le 6 septembre 1960. Les auteurs légitiment le combat contre le colonialisme en refusant de prendre les armes ou en apportant une aide concrète aux Algériens. À l'initiative de Marcel Péju, Maurice Blanchot, Dyonis Mascolo et Claude Lanzmann aidés de Jérôme Lindon qui suggère une première liste de signataires à 121, la liste comprend d'illustres personnalités de la culture: François Maspero, Jérôme Lindon, Françoise Sagan, Édouard Pignon, Robert Lapoujade, André Masson, Sartre, Beauvoir, Alain Resnais, Simone Signoret, Alain Robbe-Grillet, etc. Certains d'entre eux sont appelés à témoigner lors du procès, comme c'est le cas pour Claude Lanzmann, Nathalie Sarraute, Claude Roy, Jérôme Lindon, André Mandouze, etc.

Le manifeste crée de vifs débats dans l'espace public et devient un élément-clé du procès, amplifiant de fait sa médiatisation ${ }^{85}$.

45 Féru de procès, Paris Match rapporte successivement le procès Dominici en 1954, le procès d'Eichmann à Jérusalem en 1961 et des généraux séditieux, Lagaillarde et Challe après le putsch en avril 1961. En revanche, rien n'est rapporté au sujet du procès Jeanson $^{86}$. La seule mention arrive le $1^{\text {er }}$ octobre 1960 et concerne seulement l'implication de Sartre. Un éditorial en début de magazine est titré : « Sartre machine à guerre civile ${ }^{87} »$ dénonçant les propos de ce dernier lors du procès Jeanson. En effet, la réaction de Sartre, proche de Francis Jeanson, était très attendue. Une lettre, appuyant le combat des "porteurs de valises », est lue lors du procès. Or, Sartre était alors en voyage au Brésil. Il ne prend connaissance du contenu de la lettre, qui consacre d'ailleurs l'expression de " porteurs de valise ", qu'à son retour. Il refuse de rentrer à la demande de Marcel Péju, et c'est ce dernier, au nom de l'équipe des Temps modernes qui rédige la lettre après autorisation de Sartre de la signer en son nom et de la transmettre au tribunal ${ }^{88}$.

46 Paris Match ne fait absolument pas état non plus de l'arrestation et du viol de Djamila Boupacha. Ce sont au contraire des images de «paix » entre les communautés qui sont privilégiées.

47 Restant noyée dans l'information nationale, «people » et internationale, l'actualité algérienne est en revanche systématiquement discutée, à travers une nouvelle rubrique «Editorial» en début du magazine. Par ailleurs, les pages publicitaires augmentent significativement, l'arrivée du colorama, soit de l'utilisation importante de la couleur en photographie et dans les publicités, et l'insertion de suppléments, quelquefois détachables, achèvent de faire entrer la revue dans la modernité. Lorsqu'il s'agit de défendre la politique du général de Gaulle après sa déclaration sur le principe d'autodétermination, en septembre 1959, la revue adopte le langage de l'exécutif et du plaidoyer. «Le sujet brûlant de l'Algérie » est traité dans un dossier Algérie de presque vingt pages, où Raymond Cartier interroge : «l'Algérie vaut-elle la peine d'être gardée ? ${ }^{89} »$ Les conditions d'un État fédéral où les minorités seraient respectées sont débattues. Le traitement iconographique ici se veut plus scientifique; le texte est dominant et s'accompagne de différentes cartes géographiques de l'Algérie. 

30 janvier 1960 contient un supplément spécial Algérie où des images documentent le retranchement des généraux Lagaillarde et Ortiz $^{90}$ ainsi que le rassemblement de la foule en plein centre d'Alger. D'autres montrent les gendarmes à terre victimes d'une fusillade ${ }^{91}$. Dans le numéro suivant, du 6 février 1960, les " heures tragiques d'Alger " font la Une. Les photographies des barricades érigées par les Français d'Algérie côtoient l'image des cercueils alignés lors de la cérémonie officielle rendue en l'honneur des 14 gendarmes morts. Un long article détaille «le drame vu de Paris» et la réaction du général De Gaulle qui affirme que «l'ordre doit être rétabli $»^{92}$. L'ambivalence de la revue se manifeste lorsqu'elle s'aligne sur les propos de De Gaulle tout en privilégiant des photographies flatteuses des militaires séditieux ${ }^{93}$.

Bien qu'une sémantique de l'opposition perdure, pour la première fois dans le numéro du 2 juillet 1960 l'Algérie en tant que pays à part entier apparait en Une dans laquelle Ferhat Abbas est photographié aux côtés de De Gaulle.

Fig. 20.

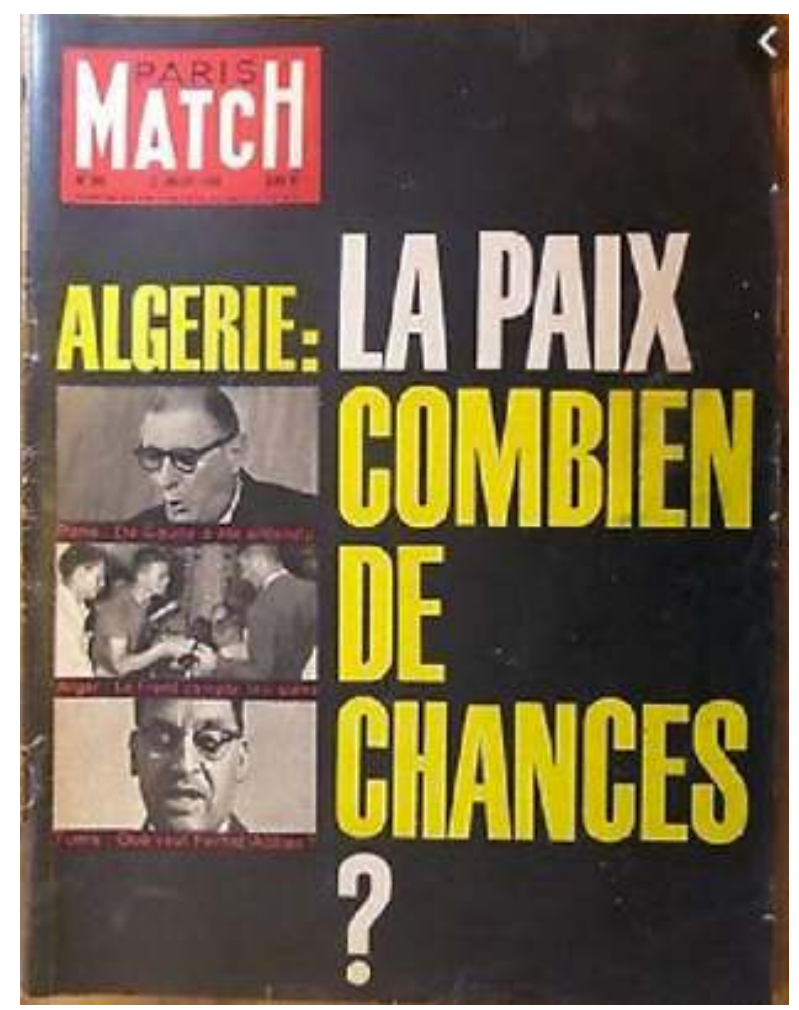

Paris Match, n586, 2 juillet 1960.

(C) D.R.

\section{Une paix sur fond de violences}

L'affirmation du droit à l'autodétermination modifie la politique française vis-à-vis de l'Algérie. Au début de l'année 1961, le contingent et la population sont photographiés votant en faveur du référendum pour le droit à l'autodétermination. Le portrait de Ben Bella est reproduit, à partir de mars 1961, dans le cadre du «dossier secret des négociations » avec De Gaulle ${ }^{94}$. Les chefs du Gouvernement provisoire de la République 
Algérienne deviennent de plus en plus présents ${ }^{95}$. Ben Khedda est mis à l'honneur dans une nouvelle rubrique, " ces hommes qui font l'événement ", du 9 septembre $1961^{96}$. Le conflit est abordé au travers de la question de la paix et des négociations difficiles entre gouvernement français et FLN, entre FLN et OAS également. Car l'année 1961 est également celle de la création de l'Organisation de l'armée secrète. La revue rapporte alors les différents attentats qu'elle commet en France, notamment celui à la mairie d'Évian, lieu des négociations ${ }^{97}$. Les images de violences, de blessés et de lieux démolis s'accumulent $^{98}$. Là encore, les blessés français sont montrés rapidement secourus. Le putsch d'Alger apparaît en Une du 6 mai 1961.

Fig. 21.

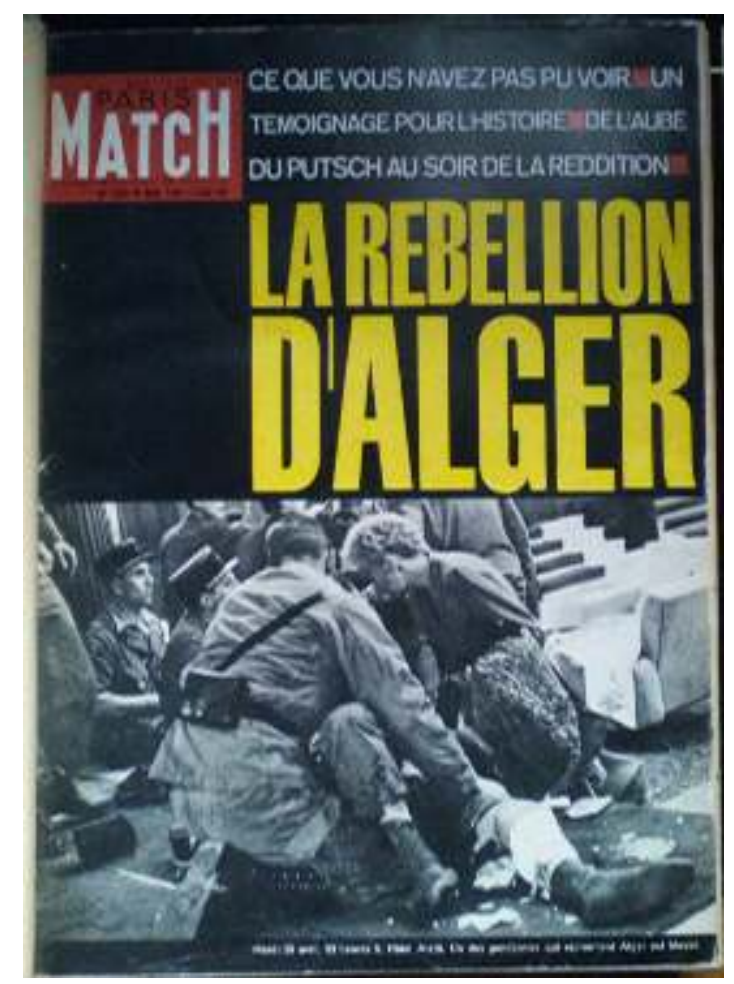

Paris Match, n 630, 6 mai 1961.

(C) D.R.

51 Les images des militaires séditieux restent très présentes ; leur action est détaillée aux lecteurs et ces derniers sont régulièrement informés de leur fuite en Espagne et de leur procès après leur arrestation ${ }^{99}$. Le massacre du 17 octobre 1961 fait la Une du numéro 655 du 28 octobre 1961 et Paris Match traite le sujet comme un fait divers. Une photographie montre des personnes, mains en l'air, sortant du métro et escortées par des gendarmes. Elle est accompagnée du titre suivant: "Le drame arrive en métro ». L'un des sous-titres énonce que « des milliers de travailleurs nord-africains sont venus de leurs banlieues ignorées et surgissent, inquiétants, sous les lumières de la ville ». Le lecteur découvre ensuite une foule massive et agitée dans les rues de Paris. La répression apparaît au travers de deux cadavres étendus au sol quand d'autres personnes se sont réfugiées près d'un mur. Cette série de photographies se termine par des images de l'arrestation des manifestants, encore une fois montrés soumis à l'autorité, les mains en l'air et entrant dans un autobus qui les mènera au Palais des sports. 
Fig. 22.

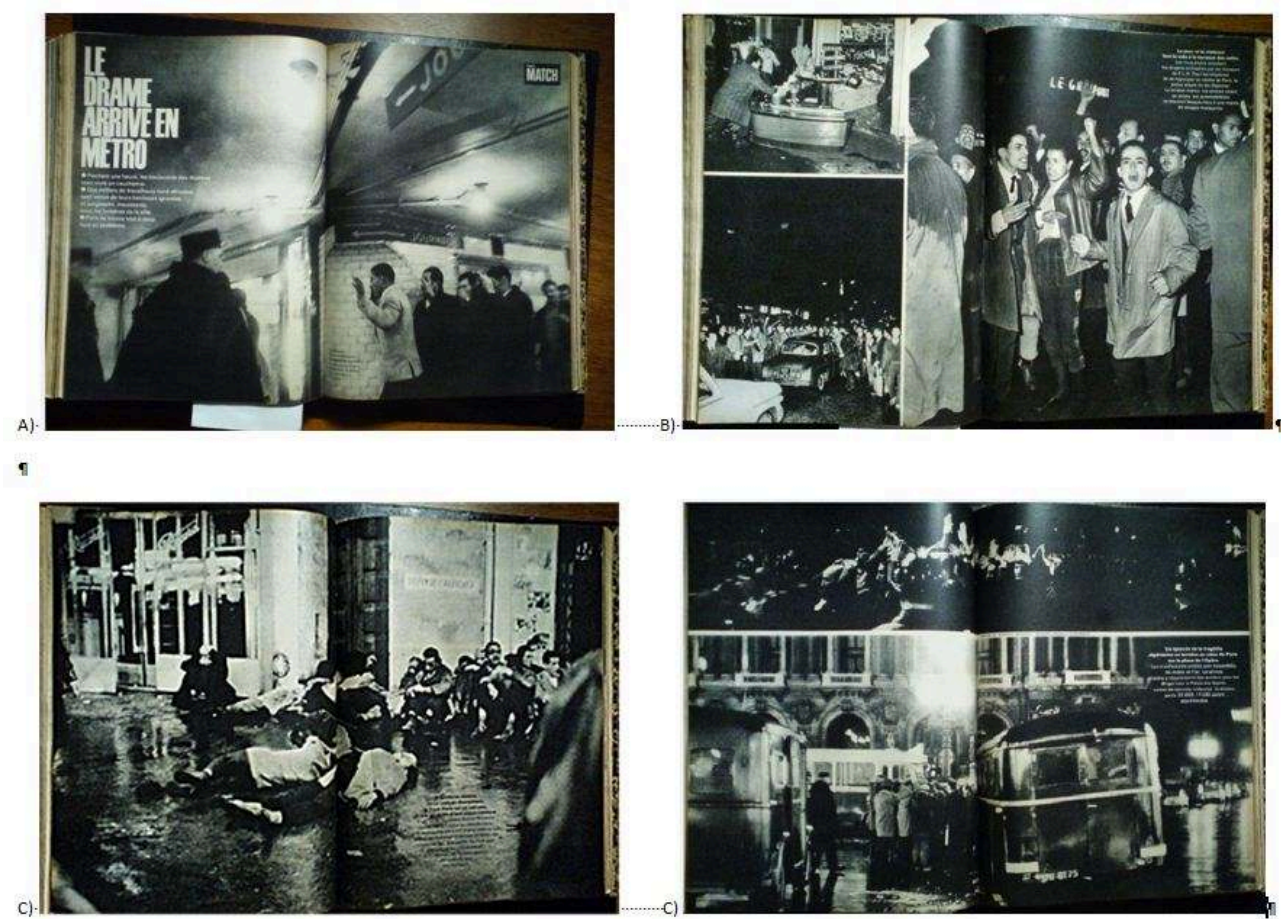

Paris Match, $n^{\circ} 655,28$ octobre 1961

(C) D.R.

52 À partir de 1962, la question algérienne fait les gros titres en Une. En mars, toutes les Une sont consacrées à l'Algérie. Le traitement du conflit évolue à travers les différentes rubriques dans lesquelles il est développé : d'abord dans la rubrique " Actualité », puis à partir de mai dans la rubrique "affaire algérienne » et enfin à partir de juillet dans celle « le monde» qui acte la décolonisation (fig. 23A). Le ton sensationnel perdure quand de nouveaux thèmes sont introduits - les négociations, le terrorisme de l'OAS, le sort des "harkis ", " pieds-noirs » et bien sûr l'arrivée des nouveaux dirigeants, notamment de Krim Belkacem, en Algérie (fig. 23B).

Fig. 23.

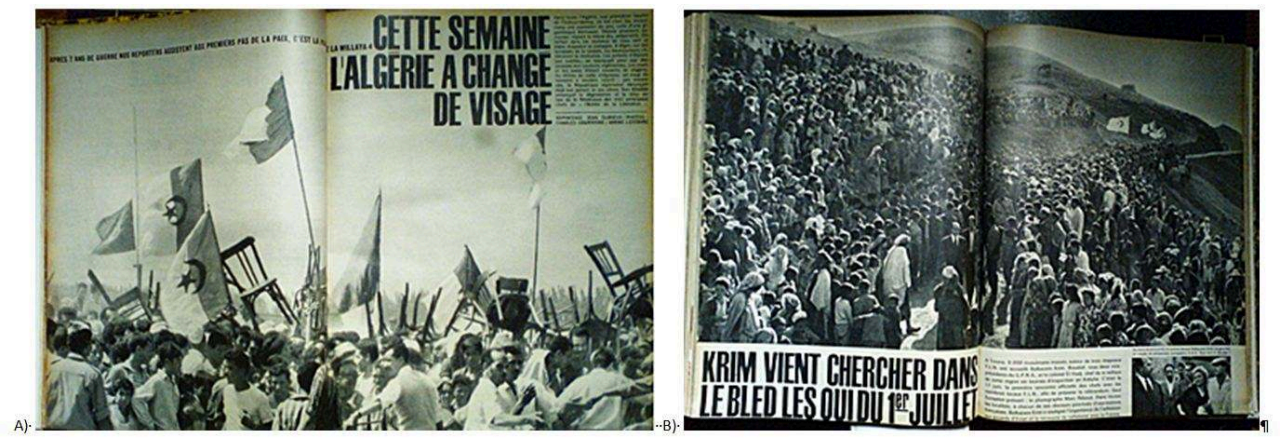

A) Paris Match, n 691, 7 juillet 1962. B) Paris Match, n 690, 30 juin 1962. (C) D.R. 
Les luttes de pouvoir qui s'ensuivent sont discutées ${ }^{100}$. Le journal rapporte aussi régulièrement les violences subies par les Européens d'Algérie et les «Harkis » ${ }^{101}$. Un reportage est consacré à l'arrivée des « pieds-noirs » en métropole.

Fig. 24.

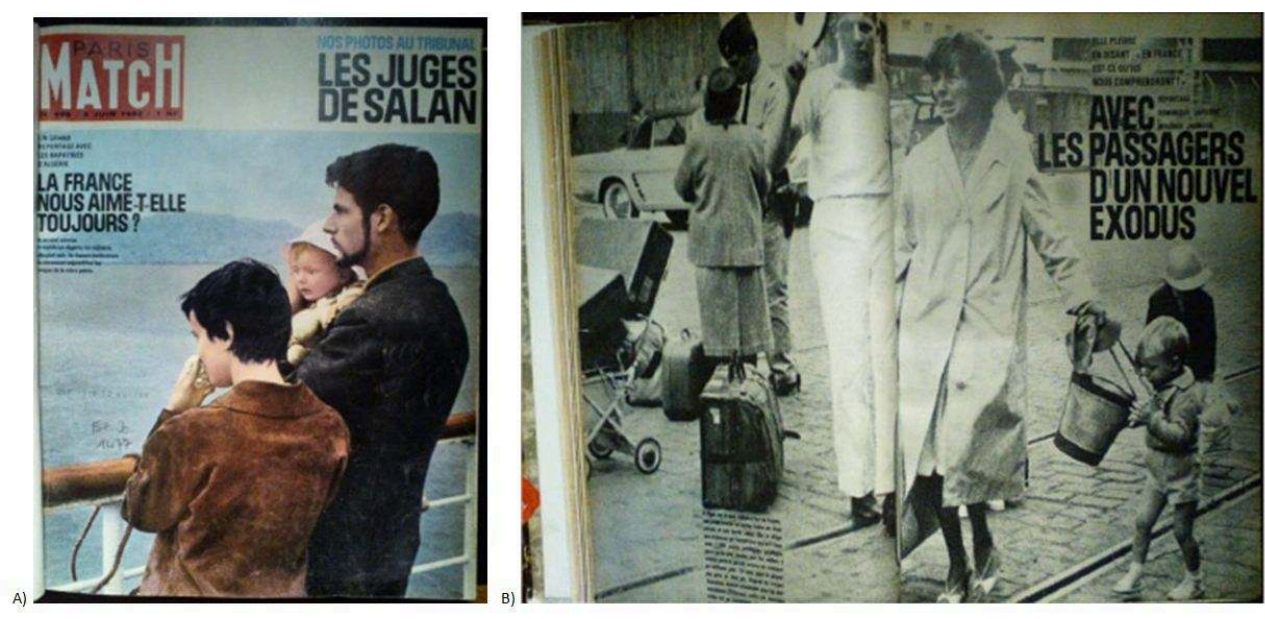

Paris Match, $n^{\circ}$ 686, 2 juin 1962.

(c) D.R.

\section{Conclusion}

Ainsi, malgré son orientation idéologique, Paris Match a de toute évidence participé à construire une histoire visuelle de la guerre d'indépendance algérienne. Cet échantillon montre à quel point son fonds photographique est massif, sachant en outre, que le magazine réalisait une sélection et ne publiait pas toutes les photographies prises par ses photoreporters. Les images publiées témoignent du fossé qui séparait la métropole et son ancienne colonie ainsi que de l'évolution des mentalités, en France, face à une décolonisation difficile. Son étude nous interroge également sur les imaginaires construits autour de l'Autre et de la guerre. La guerre d'indépendance algérienne a longtemps été qualifiée de guerre "sans nom», "sans images " archives nous prouve le contraire, bien que ce soit de manière orientée idéologiquement, la guerre était non seulement nommée mais aussi montrée. Le retour aux sources primaires nous permet par conséquent de mieux déconstruire les discours de domination véhiculés et qui imprègnent sans doute encore aujourd'hui nos imaginaires.

\section{NOTES}

1. L. Gervereau, J.P. Rioux, B. Stora, La France en guerre d'Algérie, novembre 1954-juillet 1962, Cat. Exp., Musée d'Histoire Contemporaine - BDIC, Paris, Exposition du 4 avril au 28 juin 1992, p. 228. 
2. Sur la censure dans la presse, voir l'article de Christophe Barthélémy, dans L. Gervereau, J.P. Rioux, B. Stora, La France en guerre d'Algérie, novembre 1954-juillet 1962, op. cit.

3. Ibid., p. 122. Les saisies sont plus importantes sous la $\mathrm{V}^{\mathrm{e}}$ que sous la $\mathrm{IV}^{\mathrm{e}}$ République. Les années les plus fortes de saisies sont : 1960 (154), 1961 (127) et 1962 (120).

4. La revue met en avant la perspective française en rapportant régulièrement la « réaction de Paris ».

5. Paris Match, $n^{\circ} 293$, du 13 au 20 novembre 1954.

6. Paris Match, $\mathrm{n}^{\circ} 293$, du 13 au 20 novembre 1954 ; Paris Match, $\mathrm{n}^{\circ} 438,22$ juin 1957 ; Paris Match, $\mathrm{n}^{\circ}$ 464, $1^{\mathrm{er}}$ mars 1958 ; Paris Match, $\mathrm{n}^{\circ}$ 674, 10 mars 1962 ; Paris Match, $\mathrm{n}^{\circ}$ 677, 31 mars 1962.

7. Pour exemple, les discours des représentants des différents pays à l'ONU sont mis en scène dans le Paris Match, $n^{\circ} 410,16$ février 1957. C'est la crise de mai qui est orchestrée dans le Paris Match, n 476, 24 mai 1958 ; le lecteur peut voir l'arrivée des ministres en DS tel un événement mondain.

8. Paris Match, $\mathrm{n}^{\circ} 295$, du 20 au 27 novembre 1954, et Paris Match, $\mathrm{n}^{\circ} 451$, du 30 novembre 1957, prennent la forme du roman-photo. Le traitement du fait divers est plutôt orienté sur l'assassinat des français d'Algérie. Ex : «Des vacances finies dans le sang: massacrés parce que français » (Paris Match, $\mathrm{n}^{\circ}$ 360, 13 mars 56) ; «Cible des fellagha cette famille heureuse » (Paris Match, $\mathrm{n}^{\circ}$ 352, 7 janvier 1956). La forme du roman noir est plutôt utilisée pour rapporter des évènements liés à la vie politique française. Ex : «Les nuits du régime, lumières à Matignon, fièvre chez les ministres, ronde des DS à l'Elysée » (Paris Match, $n^{\circ} 476$ du 24 mai 1958).

9. Jean Farran (1920-1998) est successivement grand reporter, rédacteur en chef puis directeur de Paris Match de 1950 à 1966. Il transforme en 1966 Radio Luxembourg en RTL et est à l'initiative de la création de la fameuse émission Les Grosses Têtes. Raymond Cartier (1904-1975), co-fondateur de Paris-Match au côté de Jean Prouvost en 1949, est nommé directeur de l'hebdomadaire. Dans les années 1930, il a milité au sein des Jeunesses patriotes. Pétainiste, il a résisté aux tentations de l'hitlérisme et est resté jusqu'à la guerre anti-allemand. Il est officier de l'état-major du maréchal de Lattre en Allemagne. Pierre Joffroy (1929-2008) est journaliste à Paris-Match de 1953 à 1976. Il écrit sur les grands procès et traquent les criminels nazis. Il publie en 1971 Eichmann par Eichmann en collaboration avec Karin Königseder. Il est également l'auteur avec Armand Gatti d'une biographie de Winston Churchill en 1954, de pièces de théâtre et du scénario de L'Enclos (1961). Il écrit aussi des romans et des nouvelles. Jean-Raymond Tournoux (1914-1984) est journaliste et historien. En 1949, il rejoint l'hebdomadaire. Durant la Seconde Guerre mondiale, après sa démobilisation, il rejoint la zone libre et devient correspondant de presse du Gouvernement de Vichy. Journaliste à la radio de Vichy et à La Légion, le maréchal Pétain le récompense de la Francisque gallique. Sa proximité avec le maréchal, qu'il accompagne dans ses déplacements, intéresse les services de renseignements. Il entre alors au service du réseau de renseignements Andalousie, dans le sous-réseau Sarrazin, sous le pseudonyme « Latour ». En mai 1949, son action au sein de ce réseau, centrée sur la recherche d'informations et le recrutement d'agents, lui vaut d'être décoré de la croix de guerre. Il est également décoré de la croix du combattant volontaire de la Résistance.

10. L. Gervereau, J.P. Rioux, B. Stora, La France en guerre d'Algérie, op. cit., p. 217 et 219.

11. Ibid., p. 217.

12. Selon Alice Cherki, Fanon le constate lors d'une visite à Paris en 1956. « Il faut dire que le contraste est saisissant entre l'atmosphère de la France et celle de l'Algérie. Il [Fanon] vient de quitter un pays où toute la population est concernée et atteinte par la guerre. » etc. A. Cherki., Frantz Fanon, portrait, Paris, Le Seuil, 2000, p. 169-170.

13. Rencontre Christian Bernadac avec François Mauriac le 24 octobre 1968 à propos de la publication du Nouveau bloc-notes 1961-1964 : « Nous avons tous été victimes de ce mensonge initial qui nous avait fait apprendre que l'Algérie c'était la France », Archives INA. F. Dosse., La Saga des intellectuels 1944-1989. I. À l'épreuve de l'Histoire 1944-1968, Paris, Gallimard, p. 316. 
14. L. Gervereau, J.P. Rioux, B. Stora, La France en guerre d'Algérie, op. cit., p. 223.

15. Ibid., p. 223.

16. Photographie de Charles Courrière, Aurès, 1955. Cf. B. Gysembergh, Paris Match, 60 ans, 60 Photographes, Paris, La Martinière, 2009, p. 82.

17. Messali Hadj (1898-1974) est un homme politique et militant nationaliste algérien. Il fut le premier à réclamer l'indépendance de l'Algérie et formera tous les futurs militants dissidents. Il fonde en 1946 le Mouvement pour le triomphe des libertés démocratiques (MTLD) qui sera interdit par la suite. Le $1^{\text {er }}$ novembre 1954 avec le déclenchement de la Révolution par le Front de libération national (FLN), qui opte pour une lutte armée, il perd de son autorité et crée le Mouvement national algérien (MNA). Ces deux mouvements (FLN et MNA) représenteront deux tendances politiques différentes et s'affronteront tout au long de la guerre.

18. Paris Match, $\mathrm{n}^{\circ} 293$, du 6 au 13 novembre 1954.

19. Paris Match, $\mathrm{n}^{\circ} 336,1^{\mathrm{er}}$ janvier $1955 ; \mathrm{n}^{\circ} 370,12$ mai $1956 ; \mathrm{n}^{\circ} 426,8$ juin $1957 ; \mathrm{n}^{\circ} 476,24$ mai 1958.

20. Paris Match, $n^{\circ}$ 328, du 9 au 16 juillet $1955 ; n^{\circ}$ 413, 9 mars 1957 ; $n^{\circ}$ 672, 24 février 1962.

21. Paris Match, $n^{\circ} 295$, du 20 au 27 novembre 1954 ; n 426, 8 juin 1957.

22. Paris Match, $\mathrm{n}^{\circ}$ 352, 7 janvier 1956.

23. LE FLN (Front de Libération national) est créé par Mohamed Boudiaf, Moustapha Ben Boulaïd, Mourad Didouche, Larbi Ben M'Hidi, Krim Belkacem, et Rabah Bitat. Afin d'obtenir l'indépendance de l'Algérie, ils optent pour une lutte armée et déclarent le début de la guerre par une série d'attentats sur le territoire algérien le $1^{\mathrm{er}}$ novembre 1954.

24. Paris Match, $n^{\circ}$ 441, 21 septembre 1957.

25. Paris Match, $\mathrm{n}^{\circ}$ 336, 3 au 10 septembre 1955.

26. Paris Match, $\mathrm{n}^{\circ} 371,19$ mai 1956.

27. Paris Match, $\mathrm{n}^{\circ}$ 370, 12 mai 1956.

28. Paris Match, $\mathrm{n}^{\circ}$ 371, 19 mai 1956.

29. Paris Match, 19 mai 1956 ; n 677, du 31 mars 1962.

30. Paris Match, 31 mars 1956 ; 7 juillet 1956 ; 31 mai 1958 ; 7 juin 1958.

31. Paris Match, $\mathrm{n}^{\circ} 363,31$ mars 1956

32. Paris Match, $n^{\circ} 441,21$ septembre 1957 ; n 406, 19 janvier 1957 ; $n^{\circ}$ 673, 31 mars 1962.

33. Paris Match, $\mathrm{n}^{\circ}$ 374, 16 juin $1956 ; \mathrm{n}^{\circ}$ 406, 19 janvier 1957.

34. Yacef Saadi (1928-) est un militant nationaliste algérien. Après le déclenchement de la Révolution, il entre en contact avec les chefs du FLN dont Rabah Bitat et Krim Belkacem et les héberge. Il devient chef de l'organisation militaire du FLN à Alger avec Ali la pointe comme adjoint. Son arrestation, le 24 septembre 1957, marque la fin de la Bataille d'Alger. Il restera emprisonné jusqu'à la fin de la guerre d'indépendance algérienne.

35. Paris Match, $n^{\circ}$ 443, 5 octobre 1957.

36. Paris Match, $\mathrm{n}^{\circ}$ 293, du 6 au 13 novembre 1954.

37. Un second portrait en pied cette fois est reproduit où Messali Hadj se promène, tête baissée, dans le $\mathrm{n}^{\circ} 512$ de Paris Match du 24 janvier 1959.

38. Ahmed Ben Bella (1916-2012), premier président de la République Algérienne est l'un des chefs historiques, lançant le début de la Révolution algérienne.

39. Alors que les cinq chefs du FLN partaient pour la conférence de Tunis après avoir été reçus par les autorités marocaines, leur avion est détourné le 22 octobre 1956 et se pose à Alger suivant un ordre des autorités militaires françaises. Ben Bella est alors emprisonné jusqu'à l'indépendance. Cet épisode crispe les relations diplomatiques franco-marocaines et fragilise la place de la France à l'ONU.

40. Paris Match, $\mathrm{n}^{\circ}$ 395, 3 novembre 1956 ; $\mathrm{n}^{\circ}$ 624, 25 mars 1961 ; n 512, 25 novembre 1961. Dès juillet 1956, sous le gouvernement de Guy Mollet, des négociations secrètes ont lieu entre Paris et le FLN. C'est après 1958 avec l'arrivée du général de Gaulle et sa déclaration sur le principe 
d'autodétermination que de véritables négociations s'organisent même si elles n'aboutissent pas. En juin 1960, une délégation algérienne accepte le dialogue avec le gouvernement français et les rencontres se poursuivent jusqu'à aboutir aux accords d'Évian le 18 mars 1962.

41. Mohammed Khider (1912-1967) sera le premier chef de l'organisation extérieure du FLN.

42. Paris Match, $n^{\circ}$ 633, 27 mai 1961. Hocine Aït Ahmed (1926-2015) est l'un des chefs historiques du FLN, membre de la délégation extérieure du FLN. Il assiste à la conférence de Bandung en avril 1955 puis séjourne à New York avant d'être arrêté en 1956 et emprisonné jusqu'à la fin de la guerre.

43. Le Gouvernement provisoire de la République Algérienne (GPRA) est créé le 19 septembre 1958 au Caire. Il se compose de dix ministres - Krim Belkacem, Mohamed Lamine Debaghine, Mahmoud Cherif, Lakhdar Bentobbal, Abdelhafid Boussouf, Abdelhamid Mehri, Ahmed Francis, M'hamed Yazid, Benyoucef Benkhedda, Ahmed Taoufik El Madani - auxquels s'ajoutent trois secrétaires d'État à l'intérieur de l'Algérie (Lamine Khène, Omar Oussedik, Mostefa Stambouli) et des quatre chefs historiques emprisonnés en France (Hocine Aït Ahmed, Ahmed Ben Bella, Mohamed Boudiaf, Rabah Bitat), désignés « ministres d'État ».

44. Krim Belkacem (1922-1970) est l'une des figures de proue de la Révolution algérienne. Chef historique, il sera également vice-président du GPRA (Gouvernement provisoire de la République Algérienne) et chef de la délégation algérienne aux accords d'Évian. Il est assassiné à Francfort en 1970.

45. Paris Match, $n^{\circ}$ 636, 17 juin 1961.

46. Amirouche (1926-1959) est un colonel de l'armée de libération nationale. D'abord militant au sein du MTLD, il rejoint les rangs de l'ALN en 1954. Il devient alors commandant de la wilaya III (Kabylie). Il meurt le 29 mars 1959 après une embuscade de l'armée française.

47. Le lecteur découvre une photographie du colonel ensanglanté. Il est allongé sur une civière entourée par des militaires. La légende annonce : «LA FIN DU COLONEL TERREUR » et une souslégende : "C'était un combat comme les autres... Parmi les cadavres restés sur le terrain, le chef sanguinaire Amirouche. Il est bien mort : la Kabylie respire. »

48. Ferhat Abbas (1899-1985) rejoint le FLN en avril 1956 et deviendra le premier président du Gouvernement provisoire de la République Algérienne.

49. Benyoucef Benkhedda (1922 -2003) coordonne avec Abane Ramdane l'action du FLN à Alger. Il se réfugie à Tunis en février 1957. En août 1961, il succède à Ferhat Abbas à la tête du GPRA.

50. Paris Match, $n^{\circ}$ 646, 9 septembre 1961.

51. Voir fig. 11, Paris Match, $\mathrm{n}^{\circ}$ 295, du 20 au 27 novembre 1954.

52. Paris Match, $\mathrm{n}^{\circ}$ 317, 30 avril 1955.

53. Paris Match, $\mathrm{n}^{\circ}$ 335, du 27 août au 3 septembre 1955.

54. Paris Match, $\mathrm{n}^{\circ}$ 317, du 23 au 30 avril 1955.

55. Le massacre de Philippeville a lieu le 20 août 1955 dans le Constantinois. Le FLN organise des manifestations violentes où des centaines d'Européens sont massacrés. La colère et l'émotion des colons et des militaires est grande. Ils réagissent en massacrant à leur tour des musulmans pris au hasard. Plusieurs centaines de victimes innocentes seront assassinées. Jusque-là, la population algérienne n'est pas très engagée du côté indépendantiste. Cet événement participera à la faire basculer du côté du FLN. Elle provoquera également l'envoi du contingent par les autorités françaises. La guerre s'intensifie. Les historiens la considèrent comme le véritable déclenchement de la guerre. Cf. B. Stora, «Le Massacre du 20 août 1955, récit historique, bilan historiographique », Revue Historical Reflections, été 2010.

56. Guy Mollet, Président du Conseil, en visite à Alger le 6 février 1956 est conspué par la foule européenne. Il revient alors à une politique de présence française en Algérie.

57. Paris Match, $\mathrm{n}^{\circ}$ 360, 13 mars 1956.

58. Paris Match, $\mathrm{n}^{\circ}$ 378, 7 juillet 1956. 
59. Les titres déclarent: "Dans le dédale de la casbah le contingent a remplacé les hommes léopards »; « Des tracts imprimés témoignent pour les jeunes qui n'ont pas marché ».

60. Selon l'historienne Raphaëlle Branche, cet événement émeut l'opinion publique. Les médias s'emparent de l'événement et affirment que les corps sont retrouvés mutilés et émasculés. Or, l'historienne explique que les preuves des mutilations sont ténues: les conclusions du médecin légiste n'ont pas été accessibles, et que seul un procès verbal de gendarmerie est disponible. Ce dernier précise qu'il y a effectivement des corps égorgés, cisaillés mais aucune émasculation. Il y a donc eu mutilations mais pas autant et pas aussi affreuses que les médias l'ont laissé dire. $\mathrm{Cf}$. R. Branche, L'Embuscade de Palestro : Algérie 1956, Paris, Armand Colin, 2010.

61. Mohamed Boudiaf (1919 - 1992) est l'un des membres fondateurs du FLN. Il est vice-président du GPRA de 1958 à 1962. Il est président de la République Algérienne quelques mois avant d'être assassiné en juin 1992.

62. Paris Match, $\mathrm{n}^{\circ}$ 395, 3 novembre 1956.

63. Cette photographie montre les cinq chefs du FLN devant un avion d'Air Maroc. Ce dernier sera détourné le 22 octobre 1956 et se posera à Alger suivant un ordre des autorités militaires françaises (les pilotes étaient français). Ben Bella sera alors emprisonné jusqu'à l'indépendance. Cet épisode crispe les relations diplomatiques franco-marocaines et fragilise la place de la France à l'ONU.

64. Paris Match, $\mathrm{n}^{\circ} 380,21$ juillet 1956.

65. Paris Match, $\mathrm{n}^{\circ} 562$ du 16 janvier 1960.

66. Paris Match $\mathrm{n}^{\circ}$ 435, 12 août 1957.

67. Paris Match, $\mathrm{n}^{\circ}$ 405, 11 janvier 1958.

68. Paris Match, $\mathrm{n}^{\circ} 451$ du 30 novembre 1957.

69. Ibid.

70. Paris Match, $\mathrm{n}^{\circ}$ 450, 11 janvier 1958.

71. Paris Match, $\mathrm{n}^{\circ}$ 562, 5 avril 1958.

72. Ibid.

73. La bataille d'Alger débute en janvier 1957 et se termine en septembre 1957 avec l'arrestation de Yacef Saadi. Cette dernière est célébrée par une photographie dans le numéro du 5 octobre 1957 de Paris Match.

74. Jeffrey James Byrne, «L'action internationale du FLN », Abderrahmane Bouchène éd., Histoire de l'Algérie à la période coloniale. 1830-1962, La Découverte, 2014, p. 651-657.

75. $\mathrm{N}^{\circ} 463$ du 22 février 1958.

76. Cette commission est censée mettre en place une médiation entre la France et l'Algérie.

77. Paris Match, $\mathrm{n}^{\circ}$ 406, 19 janvier 1957.

78. Paris Match, $n^{\circ}$ 409, 9 février 1957.

79. Ibid.

80. Paris Match, $n^{\circ} 413,9$ mars 1957.

81. Paris Match, $n^{\circ} 410,16$ février 1957

82. Paris Match, 31 mai 1958 ; 7 juin 1958 ; 14 juin 1958 ; 6 septembre 1958 ; 13 septembre 1958 ; 20 septembre $1958 ; 27$ septembre $1958 ; 4$ octobre 1958.

83. Paris Match, $\mathrm{n}^{\circ} 490,30$ août 1958.

84. Paris Match, $n^{\circ}$ 487, 2 août $1958 ; n^{\circ}$ 479, 14 juin 1958.

85. F. Dosse, La Saga des intellectuels français 1944-1989, op. cit., p. 347-354.

86. Paris Match, $\mathrm{n}^{\circ} 606,19$ novembre $1960 ; \mathrm{n}^{\circ} 607,26$ novembre 1960. Ces deux numéros rapportent le procès des instigateurs de la semaine des barricades, notamment de Lagaillarde, suivi et montré aux côtés de sa femme.

87. Paris Match, $\mathrm{n}^{\circ} 599,1^{\mathrm{er}}$ octobre 1960.

88. F. Dosse, La Saga des intellectuels français 1944-1989, op. cit., p. 359.

89. Paris Match, $n^{\circ} 520,28$ mars 1959. 
90. Pierre Lagaillarde, député d'Alger et ex-parachutiste, et Joseph Ortiz, leader du Front national français, appellent à la grève générale et à des manifestations suite au rappel du général Massu à Paris par de Gaulle et à sa déclaration sur le «droit à l'autodétermination » des Algériens. Une grande partie des Français d'Algérie se joignent à la contestation et arrivent en masse. Quand les généraux tentent de disperser la manifestation, une fusillade retentit, c'est l'escalade, le bilan officiel fait état de 22 morts dont 14 gendarmes et 92 blessés. Dans la soirée, le général Challe annonce à la radio qu'Alger est en état de siège. Les généraux se retranchent et dressent des barricades en plein Alger du 24 janvier au $1^{\mathrm{er}}$ février 1960, soutenu et ravitaillés par la population française d'Algérie. Ils conviennent d'un compromis avec Paul Delouvrier et se rendent. Pierre Lagaillarde réussi à s'enfuir en Espagne, alors qu'il est mis en liberté provisoire. Au cours du procès des Barricades, il est condamné par contumace à 10 ans de prison et Joseph Ortiz est condamné à mort. Ils seront amnistiés en 1968. Cf. B. Chastagner, O. Simoncelli, A. Mazurel, La

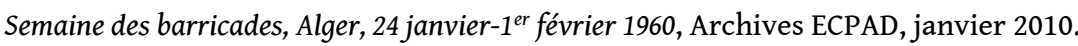

91. Paris Match, $\mathrm{n}^{\circ}$ 564, 30 janvier 1960.

92. Paris Match, $\mathrm{n}^{\circ}$ 565, 6 février 1960.

93. Paris Match, $\mathrm{n}^{\circ}$ 610, 17 décembre $1960 ; \mathrm{n}^{\circ}$ 605, 12 novembre $1960 ; \mathrm{n}^{\circ}$ 607, 26 novembre 1960.

94. Fig. 25, Paris Match, $n^{\circ} 624,25$ mars 1961.

95. Paris Match, $n^{\circ}$ 659, 25 novembre 1961.

96. Paris Match, $\mathrm{n}^{\circ}$ 646, 9 septembre 1961.

97. Paris Match, $\mathrm{n}^{\circ}$ 626, 8 avril 1961.

98. Le 4 avril 1961, un attentat de l'OAS frappe la bourse de Paris et fait 14 blessés. Paris Match, $\mathrm{n}^{\circ} 627,15$ avril 1961.

99. Paris Match, $\mathrm{n}^{\circ} 654,21$ octobre 1961.

100. Paris Match, $n^{\circ}$ 692, 14 juillet 1962.

101. Ibid.

102. Voir P. Rotman, B. Tavernier, La Guerre sans nom. Les appelés d'Algérie (1954-1962), Paris, Le Seuil, 1992 ; B. Stora, "L'hyper violence d'une guerre sans nom ", Revue Histoire, oct. 2007 ; "Algérie, guerre sans images", Médiapart, 21 sept. 2013. Toutefois, le travail de nombreux historiens va depuis quelques années dans le sens d'une déconstruction de ce mythe du " sans »; voir les travaux de Sylvie Thénault, Raphaëlle Branche ou encore Marie Chominot : M. Chominot, "Guerre des images, guerre sans image. Pratiques et usages de la photographie pendant la guerre d'indépendance algérienne (1954-1962) », Insaniyat, n 39-40| 2008, 175-195; M. Chominot, dans M. Harbi, B. Stora (dir.), La Guerre d'Algérie. La fin de l'amnésie (1954-2004), Robert Laffont, 2004

\section{RÉSUMÉS}

À partir de 1954, alors que la propagande gouvernementale nie la guerre d'indépendance algérienne et la qualifie de " pacification », Paris Match, adoptant la position du pouvoir officiel et disposant d'une équipe de 21 photos-reporters, traite de façon régulière de l'actualité algérienne. Quelle vision de la guerre véhicule la revue? Dans quelle mesure les images diffusées ont-elles contribué à façonner la mémoire - visuelle - que nous avons encore aujourd'hui du conflit ? Cet article se fonde sur les archives de Paris Match de novembre 1954 à septembre 1962. Il examine les évènements clés de la Révolution algérienne à travers l'analyse des photographies publiées par le magazine. 
From 1954, as the French government propaganda denies the Algerian War of Independence and describes it as "pacification", Paris Match, adopting the official line and working with a team of 21 photo reporters, regularly covers the Algerian news. What vision of the conflict do they convey? To what extent do the published images contribute to shaping the visual memory we still have today of the conflict? This article is based on Paris Match's archives from November 1954 to September 1962. It aims to highlight key milestones of the Algerian Revolution through the analysis of the photographs published by the magazine.

\section{INDEX}

Mots-clés : Guerre d'indépendance algérienne, décolonisation, photojournalisme, archives, Paris Match

Keywords : Algerian war, decolonization, photojournalism, archives, cultural and visual studies, Paris Match magazine

\section{AUTEUR}

\section{FADILA YAHOU}

FADILA YAHOU est doctorante en Histoire de l'art contemporain au sein du laboratoire d'Histoire sociale et culturelle de l'art (HICSA) de l'Université Paris I Panthéon-Sorbonne. Sa thèse, sous la direction de Philippe Dagen, vise à reconstituer une histoire culturelle de la guerre d'indépendance algérienne, étudiant en particulier les arts plastiques, le cinéma et la littérature, de 1955 à 1965. 